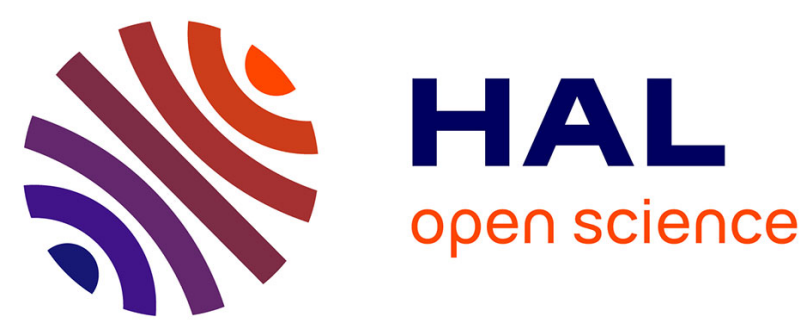

\title{
Genome-wide CRISPR-Cas9 screen reveals the importance of the heparan sulfate pathway and the conserved oligomeric golgi complex for synthetic dsRNA uptake and Sindbis virus infection
}

Olivier Petitjean, Erika Girardi, Richard Patryk Ngondo, Vladimir Lupashin, Sébastien Pfeffer

\section{To cite this version:}

Olivier Petitjean, Erika Girardi, Richard Patryk Ngondo, Vladimir Lupashin, Sébastien Pfeffer. Genome-wide CRISPR-Cas9 screen reveals the importance of the heparan sulfate pathway and the conserved oligomeric golgi complex for synthetic dsRNA uptake and Sindbis virus infection. 2020. hal-03003129

\author{
HAL Id: hal-03003129 \\ https://hal.science/hal-03003129
}

Preprint submitted on 4 Dec 2020

HAL is a multi-disciplinary open access archive for the deposit and dissemination of scientific research documents, whether they are published or not. The documents may come from teaching and research institutions in France or abroad, or from public or private research centers.
L'archive ouverte pluridisciplinaire HAL, est destinée au dépôt et à la diffusion de documents scientifiques de niveau recherche, publiés ou non, émanant des établissements d'enseignement et de recherche français ou étrangers, des laboratoires publics ou privés. 
1 Genome-wide CRISPR-Cas9 screen reveals the importance of the heparan sulfate

2 pathway and the conserved oligomeric golgi complex for synthetic dsRNA uptake and

3 Sindbis virus infection

4

5

6 Olivier Petitjean ${ }^{1, *}$, Erika Girardi ${ }^{1, *}$, Richard Patryk Ngondo ${ }^{2}$, Vladimir Lupashin ${ }^{3}$, Sébastien $7 \quad$ Pfeffer $^{1, 末}$

8

9

$10 \quad{ }^{1}$ Université de Strasbourg, Architecture et Réactivité de l'ARN, Institut de biologie moléculaire

11 et cellulaire du CNRS, 2 allée Konrad Roentgen, 67084 Strasbourg France

12

$13{ }^{2}$ Université de Strasbourg, Institut de Biologie Moléculaire des Plantes du CNRS, 12 rue du 14 Général Zimmer, 67084 Strasbourg France

15

$16{ }^{3}$ University of Arkansas for Medical Sciences, 4301 West Markham Street, Little Rock, 17 Arkansas 72205, United States of America

18

$19 *$ These authors contributed equally. Author order was determined on the basis of increasing 20 seniority.

$22 \ddagger$ To whom correspondence should be addressed: spfeffer@unistra.fr 


\section{Abstract}

Double stranded RNA (dsRNA) is the hallmark of many viral infections. dsRNA is produced either by RNA viruses during replication or by DNA viruses upon convergent transcription. Synthetic dsRNA is also able to mimic viral-induced activation of innate immune response and cell death. In this study, we employed a genome-wide CRISPR-Cas9 loss of function screen based on cell survival in order to identify genes implicated in the host response to dsRNA. By challenging HCT116 human cells with either synthetic dsRNA or Sindbis virus (SINV), we identified the heparan sulfate (HS) pathway as a crucial factor for dsRNA entry and we validated SINV dependency on HS. Interestingly, we uncovered a novel role for COG4, a component of the Conserved Oligomeric Golgi (COG) complex, as a factor involved in cell survival to both dsRNA and SINV in human cells. We showed that COG4 knock-out led to a decrease of extracellular HS, specifically affected dsRNA transfection efficiency and reduced viral production, explaining the increased cell survival of these mutants.

\section{Importance}

When facing a viral infection, the organism has to put in place a number of defense mechanisms in order to clear the pathogen from the cell. At the early phase of this preparation for fighting against the invader, the innate immune response is triggered by the sensing of danger signals. Among those molecular cues, double-stranded (dsRNA) is a very potent inducer of different reactions at the cellular level that can ultimately lead to cell death. Using a genome-wide screening approach, we set to identify genes involved in dsRNA entry, sensing and apoptosis induction in human cells. This allowed us to determine that the heparan sulfate pathway and the Conserved Oligomeric Golgi complex are key determinants allowing entry of both dsRNA and viral nucleic acid leading to cell death. 


\section{Introduction}

Upon infection by a virus, numerous mechanisms are put in place at the cellular level to raise the alarm and get rid of, or at least limit, the invader. One of the first barrier that the virus has to overcome to is to enter the cell by taking advantage of wide diversity of ubiquitous or cellspecific cellular receptors. In addition to protein receptors, glycosaminoglycans present at the cell surface also represent crucial factors for efficient viral attachment and entry Glycosaminoglycans, and more precisely heparan sulfates are ubiquitously expressed in human cells. They possess a global negative charge that is able to interact electrostatically with the basic residues that are exposed by viral surface glycoproteins. This allows viruses to increase their concentration at cell surface and so the possibility to interact with their specific entry receptor (2). For instance, alphaviruses such as Semliki Forest virus (SFV) and Sindbis virus (SINV) are enveloped positive-strand RNA viruses that contain two glycoproteins at the envelope, the proteins E1 and E2. E2 is involved in the interaction of the virus particle to the cell surface $(3,4)$, while E1 serves in the fusion process (5).

Once inside the cell, the replication of the viral genome represents another critical step to trigger the antiviral immune response. Double-stranded (ds) RNA is a ubiquitous pathogen-associated molecular pattern (PAMP) recognized by the cellular machinery, which can arise as a replication intermediate for viruses with an RNA genome, or from convergent transcription for DNA viruses (6). In mammals, dsRNA recognition is driven by specific receptors including the cytoplasmic RIG-Like Receptors (RLRs) and endosomal Toll Like Receptors (TLRs) (7). Sensing of dsRNA by these receptors results in the activation of a complex signaling cascade leading to the production of type I interferon (IFN), which in turn triggers the expression of IFN stimulated genes (ISG) and the establishment of the antiviral state (8). The ultimate 71 outcome of this vertebrate-specific antiviral response is translation arrest and cell death by apoptosis (9). 
The revolution brought by the discovery of the CRISPR-Cas9 technology has provided biologists with an invaluable tool to edit the genome at will and easily perform individual gene knock-out (10). This technique is perfectly suited to perform genome-wide screens in a relatively fast and easy to implement manner, especially when the readout is based on cell survival. For this reason, numerous CRISPR-Cas9 loss of function screens have been performed based on cell survival after infection with different viruses (11-13). These approaches allowed the identification of novel virus-specific as well as common factors involved in antiviral defense mechanisms or in cellular permissivity to virus infection.

Here, we chose to take advantage of the fact that dsRNA is almost always detected in virusinfected cells (6) and is a potent inducer of apoptosis to design a genome-wide screen aiming at identifying host genes that when edited resulted in increased cell survival to dsRNA and viral challenge. To this aim, we performed a CRISPR-Cas9 screen based on cell survival in HCT116 cells after either cationic lipid-based transfection of an in vitro transcribed long dsRNA or infection with the model alphavirus SINV, which replicates via a dsRNA intermediate.

Our results indicate that genes involved in limiting attachment and therefore entry, be it of the synthetic dsRNA or SINV, are vastly over-represented after selection. We validated two genes of the heparan sulfate pathway (namely $S L C 35 B 2$ and $B 4 G A L T 7$ ) as required for dsRNA transfectability and SINV infectivity. We also identified and characterized COG4, a component of the Conserved Oligomeric Golgi (COG) complex, as a novel factor involved in susceptibility to dsRNA and viral induced cell death linked to the heparan sulfate biogenesis pathway.

\section{Results}

Genome-wide CRISPR/Cas9 screen based on cell survival upon dsRNA transfection identify factors of the heparan sulfate pathway

In order to identify cellular genes that are involved in the cellular response to dsRNA, which culminates with cell death, we performed a CRISPR/Cas9 genome-wide loss-of-function screen 
in the human colon carcinoma cell line HCT116. This cell line is highly suitable for

100 CRISPR/Cas9 genetic screening procedures (14) and can be easily infected with SINV with

101 visible cytopathic effects at 24 and 48 hours post infection (hpi) (Fig. S1A). Moreover,

102 transfection of an in vitro transcribed 231 bp-long dsRNA by a cationic lipid-based transfection

103 reagent in HCT116 cells led to strong cell death at 24 and 48 hours post treatment (hpt) (Fig.

104 S1B).

105 We generated a Cas9-expressing HCT116 monoclonal cell line (Fig. S1C) that we stably

106 transduced with the human genome-wide lentiviral Brunello library composed of 76441

107 sgRNAs targeting 19114 genes, as well as about 1000 non-targeting sgRNAs as controls (15).

108 We then applied a positive selection by lipofecting 30 million transduced cells per replicate

109 with the synthetic long dsRNA and we collected the surviving cells $48 \mathrm{~h}$ later. In parallel, the

110 same initial amount of stably transduced cells was left untreated as control (Input) for each

111 replicate (Fig. 1A). DNA libraries from the input samples were generated, sequenced and

112 quality checked. In particular, we verified the sgRNA coverage by observing the presence of

113 the 4 guides per genes for 18960 genes (99.2\% of the genes) and $3 \mathrm{sgRNAs}$ per gene for the

114 remaining 154 genes $(0.2 \%$ of the genes) (Dataset $\mathrm{S} 1)$.

115 Using the MAGeCK software (16), we assessed the normalized read count distribution of the

116 control and dsRNA-treated biological triplicates, which, despite a quite homogenous sgRNA

117 distribution, showed the presence of few outliers upon selection (Fig. 1B). We identified eight

118 genes that were significantly enriched with a false discovery rate lower than 1\% (FDR1\%).

119 Among those, four genes belonged to the heparan sulfate biosynthesis pathway (namely,

$120 S L C 35 B 2, B 4 G A L T 7, E X T 1$ and EXT2) and three were components of the conserved oligomeric

121 golgi complex (namely COG3, COG4 and COG8) (Fig. 1C, Dataset S2). In particular, all four

122 sgRNAs targeting each of $S L C 35 B 2, B 4 G A L T 7, C O G 4$ genes were enriched upon dsRNA

123 selection (Fig. S1D). 
124 Heparan sulfate (HS) is a linear polysaccharide that is covalently attached to core proteins in 125 proteoglycans (PG) on the cell surface (for review, see ref. (17)). Among many properties, HS 126 plays a role in binding of protein ligands and as a carrier for lipases, chemokines and growth 127 factors $(17,18)$, but also as a viral receptor (19). HS biosynthesis takes place in the Golgi, where 128 most of the biosynthetic enzymes are anchored to the Golgi membrane (20).

129 We first validated the resistance phenotype to dsRNA of SLC35B2 and B4GALT7, the two top 130 hits identified in the screen (Fig. 1C, Fig. S1D), by generating two individual knock-out clones 131 for each gene by CRISPR-Cas9 editing in HCT116cas9 cells (Fig. S2). Knock-out of either $132 S L C 35 B 2$ or B4GALT7 genes abolished cell death induced by dsRNA lipofection compared to 133 parental HCT116cas9 cells, as assessed by the measurement of cell viability $48 \mathrm{~h}$ post 134 transfection (Fig. 1D, left part of the graph). These results demonstrated the involvement of 135 SLC35B2 and B4GALT7 in dsRNA-induced cell death.

136 The observed resistance to dsRNA in the mutants could occur at many different steps: dsRNA 137 liposome attachment and entry, recognition, induction of the IFN pathway or apoptosis. To test 138 whether the first step was affected, we employed a nucleic acid delivery method that was not 139 based on cationic lipid transfection. In particular, we used nucleofection (an electroporation140 based transfection method) to introduce long dsRNAs into HCT116 cells and we showed that 141 this approach totally restored cell death in SLC35B2 and B4GALT7 knock-out cells (Fig. 1D, 142 right part of the graph). In addition, we also performed liposome-based transfection of an in 143 vitro transcribed Cy5-labelled dsRNA in SLC35B2 and B4GALT7 KO cells and assessed the 144 Cy5 fluorescence at $48 \mathrm{~h}$ post-transfection by FACS analysis (Fig. 1E-F). Although the number 145 of Cy5 positives (Cy5+) cells was not significantly different in the B4GALT7 KO clones and 146 only slightly lower in the SLC35B2 KO cells compared to WT cells (Fig. 1E), we observed a 147 significant reduction of at least $80 \%$ of the median Cy5 fluoresence in both B4GALT7 and 
148 SLC35B2 KO cells relative to control (Fig. 1F), thereby indicating a significant drop in the 149 number of transfected Cy5-labeled RNA molecules per cells.

150 We also confirmed that liposome-based transfection of nucleic acid such as plasmidic DNA 151 was impaired in $S L C 35 B 2$ and B4GALT7 KO cells, by transfecting a GFP-expressing plasmid 152 using Lipofectamine 2000 in wild type or knock-out cells (Fig. S3A, left panels and Fig. S3B).

153 Nonetheless, GFP expression could be restored in all cell lines upon nucleofection (Fig. S3A, 154 right panels).

155 To establish whether impairment of the HS synthesis is directly linked to a defect in dsRNA 156 entry and increased cell survival, we measured the extracellular HS levels in SLC35B2 and 157 B4GALT7 KO cells. We measured a substantial reduction of the extracellular HS staining as 158 assessed by FACS measurement of two independent SLC35B2 and B4GALT7 KO clones 159 compared to HCT116 wild type cells (Fig. 1G). To confirm the importance of HS at the cell 160 surface for liposome-based transfection, we mimicked the HS-defective phenotype by 161 removing extracellular HS in parental HCT116cas9 cells either enzymatically (with heparinase)

162 or chemically (with sodium chlorate $\mathrm{NaClO} 3$ ) (Fig. S3C-D). We tested the transfectability of a

163 GFP-expressing plasmid by measuring either the relative number of GFP positive cells or the 164 relative median of GFP intensity of fluorescence by FACS analysis. Although the relative 165 number of GFP positive cells was not significantly reduced by heparinase treatment (Fig. S3C), 166 it caused a reduction in GFP intensity in HCT116cas9 treated cells, thereby recapitulating the

167 GFP plasmid lipofection defect observed in SLC35B2 and B4GALT7 KO (Fig. S3D). Moreover, 168 this effect correlates with the reduction of extracellular HS by enzymatic treatment quantified 169 by FACS (Fig. S3E), which demonstrates that extracellular HS are crucial for transfection by 170 lipofection. In the case of $\mathrm{NaClO} 3$ treatment, despite the reduction in both the relative number 171 of GFP positive cells (Fig. S3C) and the relative median of GFP intensity of fluorescence(Fig. 172 S3D) compared to control, we could not observe a correlation with a decrease in overall 
extracellular HS (Fig. S3E). This could be due to the fact that while a mix of heparinase I \& III remove every kind of extracellular heparan sulfates, $\mathrm{NaClO} 3$ only impairs the O-sulfation (21). Taken together, our results show that knocking out $S L C 35 B 2$ and $B 4 G A L T 7$ results in reduced levels of extracellular HS, which in turn impairs liposome-based transfectability of HCT116 cells. Moreover, the validation of these two top hits indicates that other candidates might be suitable for further analysis and may also have an impact on the dsRNA resistance phenotype.

COG4 is involved in dsRNA-induced cell death partly via the heparan sulfate pathway

Among the significant hits of our genome-wide screen were proteins related to COG complex, namely COG4, COG3 and COG8. The COG complex is a hetero-octameric complex containing 8 subunits (COG1-8) interacting with numerous proteins mainly involved in intra-Golgi membrane trafficking such as vesicular coats, Rab proteins and proteins involved in SNARE complex $(22,23)$. This interaction with the trafficking machinery is crucial for the proper

187 problems such as glycosylation defect (24-27), which are due to mislocalization of recycling

188 Golgi enzymes $(28,29)$.

189 Since we retrieved three out of the eight COG family members in our CRISPR/Cas9 screen 190 suggesting their importance in dsRNA-induced cell death, we tested the effect of their 191 inactivation by CRISPR-Cas9. COG4 being the most enriched COG gene in our screen, we 192 generated a polyclonal COG4 KO HCT116cas9 cell line and validated their dsRNA resistance 193 phenotype resulting in an increase survival in response to synthetic dsRNA transfection (Fig. 194 S4A). We also observed a reduction in the relative number of Cy5 positives (Cy5+) cells and 195 the median Cy5 fluorescence in COG4 KO cells relative to control by FACS analysis (Fig. 196 S4B-C). 
To further confirm the involvement of the COG complex, we also tested the effect of dsRNA transfection in previously generated HEK293T KO COG3, 4 and 8 cells (Fig. 2A) (30). Interestingly, while COG8 mutants did not display a significant survival phenotype in response to dsRNA lipofection, COG3 and COG4 KO HEK293 cells did. In addition, the survival phenotype could be complemented by stable expression of a COG4-GFP construct compared to COG4 KO cells (Fig. 2A). Moreover, although we could not detect a decrease in the relative number of $\mathrm{Cy} 5$ positives (Cy5+) cells in COG4 $\mathrm{KO}$ cells relative to the controls (Fig. 2B), the median Cy5 fluorescence in COG4 KO cells was significantly reduced compared to both HEK293T and COG4 rescued cells (Fig. 2C), thereby indicating a significant decrease in the number of transfected Cy5-labeled RNA molecules per cells.

In agreement, dsRNA accumulation appeared to be significantly reduced, but still present, in HEK293T COG4 KO cells compared to control cells as determined by RT-qPCR analysis of dsRNA isolated from cells $24 \mathrm{~h}$ after transfection (Fig 2D) and this correlated with reduced IFNbeta accumulation in HEK293T KO COG4 cells compared to control cells (Fig. 2E).

These results indicated that dsRNA transfectability was strongly reduced but not totally impaired in the absence of COG4 and that dsRNA could be still detected in COG4 KO cells in order to activate type-I IFN response.

214 We confirmed the reduced internalization of dsRNA in COG4 mutant cells by transfecting 215 rhodamine-labeled poly(I:C), a synthetic dsRNA analog, in HEK293T COG4 KO or WT cells 216 (Fig. 2F) and by counting the number of poly I:C foci per cell at 6,12 and $24 \mathrm{~h}$ post transfection 217 (Fig. 2G). We could observe a significant reduction in rhodamine positive foci in HEK293T 218 COG4 KO during the time course, suggesting a defect in dsRNA internalization, which could 219 explain the increased survival phenotype.

220 In order to assess whether the COG4 KO survival phenotype was associated with a defect in 221 the heparan sulfate pathway, we stained extracellular HS and measured the HS expression by 
FACS analysis. We observed a decrease of extracellular HS in KO COG4 cells compared to control cells (WT and rescued), which demonstrated that the COG complex is related to the HS biosynthesis pathway (Fig. S4D)

The reduction in extracellular HS could correlate with a decrease in transfectability and explain the survival phenotype in KO COG4 cells. Surprisingly however, lipofection of a GFP expressing plasmid indicated that HEK293T COG4 KO cells are still transfectable with a plasmid DNA compared to control cells as observed by FACS analysis (Fig. S4E-F).

Altogether these findings indicate that the COG complex is involved in HS biosynthesis and that removal of COG4 results in a lower accumulation of HS at the cell surface, which most

231 likely translates in a reduced transfectability of dsRNA. However, as opposed to the 232 observations in $S L C 35 B 2$ or $B 4 G A L T 7 \mathrm{KO}$ cells, the cells are still transfectable with a plasmid 233 DNA and, although to a lower extent, with dsRNA. Interestingly, the increased cell survival 234 phenotype of COG4 KO cells upon dsRNA transfection does correlate with a reduced, but still 235 measurable, IFN- $\beta$ production.

Cell survival based genome-wide CRISPR/Cas9 screen identifies COG4 as a permissivity

239 SINV is a small enveloped virus with a single stranded RNA genome of positive polarity. The

240 virus belongs to the Togaviridae family, alphavirus genus and is considered as the model for 241 other medically important viruses such as chikungunya virus (CHIKV) and Semliki forest virus 242 (SFV). During its infectious cycle, SINV produces dsRNA as a replication intermediate and 243 induces cytopathic effects in mammalian cells, leading to cell death within 24 to $48 \mathrm{~h}$ post244 infection (31).

245 In order to identify host genes that are related to SINV-induced cell death and infection, we 246 performed a CRISPR/Cas9 knock-out screen in HCT116cas9 cells, which are susceptible to 
this virus (Fig. 3A, Fig. S1). After transduction with the CRISPR lentiviral genome-wide knockout library, puromycin-resistant HCT116 cells were infected with SINV-GFP at a MOI of 0.1 and selected for cell survival. Using the MAGeCK software (16), we assessed the normalized read count distribution of the control and SINV-infected biological triplicates, which, despite a quite homogenous sgRNA distribution, showed the presence of few outliers 252 upon selection (Fig. 3B). We identified two genes that were significantly enriched with a false 253 discovery rate lower than 25\% (FDR25\%), notably SLC35B2 and B4GALT7 (Dataset S3, Fig. $2543 \mathrm{C}$ ). Genes of the heparan sulfate pathway have been previously found in genome-wide CRISPR-Cas9 loss of function studies looking for factors involved in the accumulation of 256 viruses such as Influenza, Zika and chikungunya virus (11, 32, 33). Interestingly, among the 257 top-ranking hits, we retrieved COG4, which was not previously associated with SINV infection 258 (Fig. 3C).

259 To validate the involvement of COG4 during SINV infection, we infected HEK293T, COG4 260 KO or COG4 KO rescued HEK293T cells with SINV and measured cell viability at 24, 48 and 26172 hpi. The cell viability assay revealed that the COG4 KO cells were less sensitive at early 262 times points of SINV infection ( $24 \& 48 \mathrm{hpi}$ ), but this tendency disappeared at $72 \mathrm{hpi}$ (Fig. 3D. 263 In agreement, the determination of viral titer by plaque assay showed that COG4 KO HEK293T 264 cells produced significantly less infectious viral particles than HEK293T or COG4-rescued 265 cells at $24 \mathrm{hpi}$ but not at $48 \mathrm{hpi}$, underlining a possible delay in the infection and virus-induced 266 cell death (Fig. 3E). We also observed that GFP accumulated to lower levels in COG4 KO than 267 in WT cells both at 24 and 48 h post-infection (hpi) (Fig. S5A). Finally, we noticed that the 268 reduced viral production in COG4 $\mathrm{KO}$ cells was associated with a reduced accumulation of 269 viral dsRNA in the cytoplasm, when we infected WT or COG4 KO cells with SINV-GFP and 270 performed immunostaining with the anti-dsRNA J2 antibody 24 hpi (Fig. S5B). Overall, our 
results indicate that COG4 expression is needed for an efficient SINV infection and that its absence can delay the infection thereby increasing cell survival in COG4 KO cells.

\section{Discussion}

Several CRISPR/Cas9 screens aiming at identifying factors required for infection by specific viruses have been described in the literature, but to our knowledge, none has been designed to look at the effect of the only common factor between all those viruses, i.e. dsRNA. Here, we used the Brunello sgRNA lentiviral library to screen for genes involved in HCT116 cells survival to synthetic dsRNA transfection and to SINV infection. This allowed us to identify components of the heparan sulfate biosynthesis pathway and of the COG complex as critical

281 host factors in the cellular response to above mentioned challenges. It has been already reported that cell-survival-based CRISPR screens for viral host factors are biased toward genes linked to the initial steps of the infection, and even more so to viral entry $(11,34)$. Thus, in our case, HS is a well-known factor required for SINV entry due to the virus adaptation to cell culture (35). We also retrieved genes of the HS pathway in our dsRNA-based screen, and we confirmed the importance of extracellular HS for dsRNA-induced toxicity. This is mostly due to a decrease of transfectability of the cells when HS are missing, which is linked to the fact that the polyplexes used for transfection are positively charged and can interact electrostatically with glycosaminoglycans $(36,37)$. Our work also points out to the limitations of survival-based

CRISPR-Cas9 screens. Thus in this study the selection pressure was too strong to allow the

291 identification of genes intervening after the entry step, thereby making the screen less sensitive. Optimizing the selection procedure, e.g. by adjusting the concentration of dsRNA, or the

294 transfection, but at the expense of specificity. Alternatively, new strategies should be designed 295 to overcome this problem, such as using fluorescent-based cell sorting in order to be less stringent in the selection. 
In addition to the HS pathway, we identified members of the COG complex, and more specifically COG4, as factors involved in dsRNA transfection and SINV infection. Loss of function COG4 mutant cells show a dsRNA-resistant phenotype as well as a reduction in extracellular HS expression, similar to previously published reports for other COG proteins (33, 38). Surprisingly, even if the removal of COG4 expression results in a defect in the HS pathway, we were still able to transfect the KO COG4 cell line either with a plasmid encoding GFP or, although to a lesser extent, dsRNA. In addition, the dsRNA molecules that are able to enter into that the innate immune response is still functional in these mutant background. Nonetheless, cell death induced by dsRNA appears to be lower in COG4 KO cells, most likely due to a delay 307 in the infection.

308 Future work will be needed in order to assess whether this phenotype upon SINV infection is 309 only correlated with a defect in HS biogenesis in COG4 mutants or to other function of COG4.

310 The fact that COG4 KO cells seem to better survive to both synthetic dsRNA transfection and 311 viral infection opens several interesting perspectives. Indeed, since the COG complex is related 312 to glycosylation and membrane trafficking $(23,25,39,40)$, deficiency in one or more of its 313 components could potentially lead to a glycosylation and/or subcellular localization defect of 314 components of the innate immune response or of the apoptosis pathway, although this 315 possibility remains to be formally proven. The difference of transfectability of plasmid DNA 316 and dsRNA in COG4 $\mathrm{KO}$ cells is also intriguing and could indicate that different kinds of 317 nucleic acids do not necessarily use the exact same routes to enter the cells upon liposome318 based transfection. Finally, there could be other defects linked to COG deficiencies $(39,41)$ that 319 could account for our observations and elucidating those will require further work. It is 320 particularly interesting that COG3 and COG4 knock-out cells display a dsRNA-induced cell 
death resistance phenotype, while COG8 mutants do not. This implies that only part of the COG complex is involved in dsRNA uptake.

In conclusion, our work uncovered COG4 as a new player in the HS production, which is required for both SINV infection and dsRNA transfection. These results also highlight that synthetic dsRNA is a powerful tool to identify novel key pathways of the cellular response to RNA viruses.

\section{Materials and Methods}

\section{Cell culture and virus}

330 HCT116, HEK293T, HEK293T COG KOs, BHK21 and Vero R cells were maintained in 331 Dulbecco's Modified Eagle Medium (DMEM) $4.5 \mathrm{~g} / \mathrm{L}$ glucose (Gibco, Thermo Fisher 332 Scientific Inc.) supplemented with 10\% fetal bovine serum (FBS) (Takara) in a humidified 333 atmosphere of $5 \% \mathrm{CO}_{2}$ at $37^{\circ} \mathrm{C}$. HEK293T COG3, COG8 and COG4 $\mathrm{KO}$ and $C O G 4 \mathrm{KO}$ stably 334 rescued with COG4-GFP were described previously (42, 43). HCT116cas9 and HEK293T 335 COG4rescued were maintained in the same medium with addition of $10 \mu \mathrm{g} / \mathrm{mL}$ blasticidine. 336 HCT116 KO clones (COG4, SLC35B2\#1 and \#2, B4GALT7\#1 and \#2 were maintained in the 337 same medium with addition of $10 \mu \mathrm{g} / \mathrm{mL}$ blasticdine and $1 \mu \mathrm{g} / \mathrm{mL}$ puromycine.

338 SINV wild type (SINV) or expressing the green fluorescent protein (SINV-GFP) were produced 339 as previously decribed (44) in BHK21 cells. In the later, the promoter of SINV subgenomic 340 RNA was duplicated and inserted at the 3' extremity of the viral genome, the GFP sequence 341 was then inserted after this new promoter. Cells were infected with either SINV WT or SINV 342 GFP at a MOI of $10^{-1}$ and samples were harvested at 24 or 48 hours post-infection (hpi).

\section{Standard plaque assay}


10-fold dilutions of the viral supernatant were prepared. $50 \mu 1$ aliquots were inoculated onto

346 Vero R cell monolayers in 96-well plates for 1 hour. Afterwards, the inoculum was removed 347 and cells were cultured in $2.5 \%$ carboxymethyl cellulose for $72 \mathrm{~h}$ at $37^{\circ} \mathrm{C}$ in a humidified 348 atmosphere of $5 \% \mathrm{CO}_{2}$. Plaques were counted manually under the microscope. For plaque 349 visualization, the medium was removed, cells were fixed with $4 \%$ formaldehyde for 20 min and 350 stained with $1 \mathrm{x}$ crystal violet solution (2\% crystal violet (Sigma-Aldrich), $20 \%$ ethanol, $4 \%$ 351 formaldehyde).

\section{J2 immunostaining}

354 HEK293T or KO COG4 HEK293T cells were plated on millicell EZ slide (Millipore) and were 355 infected with SINV at an MOI of 0.1 for $24 \mathrm{~h}$. Cells were fixed with $4 \%$ formaldehyde diluted in PBS $1 \mathrm{x}$ for $10 \mathrm{~min}$ at room temperature, followed by incubation in blocking buffer $(0.2 \%$ Tween X-100; PBS 1x; 5\% normal goat serum) for $1 \mathrm{~h} . \mathrm{J} 2$ antibody (Scicons) diluted in blocking buffer at 1:1000 was incubated over night at $4^{\circ} \mathrm{C}$. Between each steps, cells were washed with PBS 1X-Tween 0.2\%. Secondary antibody goat anti-mouse Alexa 594

360 (ThermoFisher) diluted at 1:1000 in PBS $1 \mathrm{x}$-Tween $0.2 \%$ were incubated for $1 \mathrm{~h}$ at room temperature. After DAPI staining (1:5000 dilution in PBS 1x for $5 \mathrm{~min}$ ), slides were mounted with a coverslip over anti-fading medium and observed by epifluorescence microscopy using 363 the BX51 (Olympus) microscope with a X 40 objective.

\section{Generation of HCT116cas9 line}

366 The HCT116cas9 cells, expressing human codon-optimized S. pyogenes Cas9 protein, were 367 obtained by transducing wild type HCT116 colorectal carcinoma cell line (ATCC® CCL$368247^{\mathrm{TM}}$ ) with lentiCas9-Blast lentiviral vector (Addgene \#52962). Briefly, wild-type HCT116 369 cells were cultured in standard DMEM (GIBCO) medium supplemented with 10\% Fetal bovine 
serum (FBS, Gibco) and $100 \mathrm{U} / \mathrm{mL}$ of penicillin-Streptomycin (Gibco) at $37^{\circ} \mathrm{C}$ in $5 \% \mathrm{CO}_{2}$. The cells were transduced at $80 \%$ confluency in a $10 \mathrm{~cm}$ tissue culture plate, using $6 \mathrm{~mL}$ lentiviral supernatant supplemented with $4 \mu \mathrm{g} / \mathrm{mL}$ of polybrene (H9268, sigma) for 6 hours. The transduction medium was replaced with fresh growing medium for $24 \mathrm{~h}$ before starting the selection. Transduced HCT116cas9 cells were selected for 10 days and maintained in growing medium supplemented with $10 \mu \mathrm{L} / \mathrm{mL}$ of Blasticidin (Invivogen).

\section{High titer lentiviral sgRNA library production}

The production of high titer Human sgRNA Brunello lentiviral library which contains 4 sgRNA per gene (15) (Addgene \#73178), was performed by transfecting HEK293T cells in five $15 \mathrm{~cm}$ 380 tissue culture plates using PEI (Polyethylenimin Linear, MW 25,000, 23966-1-A, Polysciences) transfection method (45). Briefly, for each $15 \mathrm{~cm}$ plate containing $20 \mathrm{~mL}$ of medium, $10 \mu \mathrm{g}$ of sgRNA library, $8 \mu \mathrm{g}$ of psPAX2 and $2 \mu \mathrm{g}$ of pVSV diluted in $500 \mu \mathrm{L}$ of $\mathrm{NaCl} 150 \mathrm{mM}$ were

384 incubated 30 minutes at room temperature and the formed complexes were added dropwise on 385 the cells. After 6 hours, the medium was replaced and the viral supernatant was collected after 38648 hours and after 72 hours. The supernatant was filtered through a $0.45 \mu \mathrm{m}$ PES filter and the 387 viral particles concentrated 100 times using Lenti-X ${ }^{\mathrm{TM}}$ Concentrator (Takara) before storage at 388 -80. The viral titer was established by counting puromycin resistant colonies formed after 389 transducing HCT116 cells with serial dilutions of viral stock. HCT116cas9 cells were 390 transduced with lentivirus-packaged Brunello sgRNA library at a MOI of 0.3. The lentiviral 391 library has been sequenced to verify that all the lenti-sgRNA are represented. 
394 For each replicate $(\mathrm{n}=3), 5 \times 10^{6}$ stably transduced cells/dish were seeded in $6 \times 15 \mathrm{~cm}^{2}$ plate in order to keep a 300X representativity of the sgRNA library. Untreated samples (Input) were collected as controls. One day later, cells were either lipofected with $1 \mu \mathrm{g} / \mathrm{mL}$ dsRNA-Citrine or infected with SINV at MOI of 0.1 and cultured at $37^{\circ} \mathrm{C} 5 \% \mathrm{CO}_{2}$. Cells were washed with PBS 1X 48 hours post treatment, to remove dead cells and fresh media was added to surviving clones. Cells were expanded and all cells were collected 6 days post dsRNA transfection and 18 days post SINV infection.

401 Genomic DNA was isolated by resuspending the cell pellet in $5 \mathrm{~mL}$ of resuspension buffer (50 $\mathrm{mM}$ Tris- $\mathrm{HCl} \mathrm{pH}$ 8.0, $10 \mathrm{mM}$ EDTA, $100 \mu \mathrm{g} / \mathrm{ml}$ RNaseA), $0.25 \mathrm{~mL}$ of $10 \%$ SDS was added and incubated 10 mins at RT after mix. After incubation, the sample was sonicated and

404 incubated 30 mins at RT with $10 \mathrm{uL}$ of proteinase $\mathrm{K}(10 \mathrm{mg} / \mathrm{mL}) .5 \mathrm{~mL}$ of Phenol/Chloroform/Isoamyl Alcohol solution was added and followed by a spin down 60 mins at $12000 \mathrm{~g} / 20^{\circ} \mathrm{C}$. Upper phase was transferred into a new tube and $500 \mathrm{uL}$ of $\mathrm{NaAc} 3 \mathrm{M}$ and 5

$407 \mathrm{~mL}$ of isopropanol was added then incubation over night at RT and followed by a centrifuge 30 $408 \mathrm{mins} / 20^{\circ} \mathrm{C} / 12000 \mathrm{~g}$. Pellet was washed using EtOH and dissolve in $\mathrm{H} 2 \mathrm{O}$.

409 Illumina P5 and P7-barcoded adaptors were added by PCR on gDNA samples according to the 410 GoTaq protocol (Promega). PCR amplicons were gel purified and sequenced on a HiSeq4000 411 (Illumina) to obtain about 30 million reads for each samples. Enrichment of sgRNAs was 412 analysed using MaGeCK with default parameters (16). Primers used to generate the PCR 413 products are listed in Table S1. The results of the dsRNA and SINV screen are available in 414 Dataset S1 and S2, respectively 
The sgRNA expression vectors targeting either SLC35B2, B4GALT7 or COG4 (sgRNA sequences selected were the 2 most enriched sgRNA from the Brunello library in the dsRNA screen) genes were produced by annealing the "sense" and "antisense" oligonucleotides (Table S1) at a concentration of $10 \mu \mathrm{M}$ in $10 \mathrm{mM}$ Tris- $\mathrm{HCl}(\mathrm{pH} 8.0), 50 \mathrm{mM} \mathrm{MgCl} 2$ in $100 \mu \mathrm{L}$. The mixture was incubated at $95{ }^{\circ} \mathrm{C}$ for 5 minutes and then allowed to cool down to room temperature. The oligonucleotide duplex thus formed was cloned into the BbsI restriction site of the plasmid pKLV-U6gRNA (BbsI)-pGKpuro2ABFP (Addgene\#62348). The lentiviral supernatant from single transfer vector was produced by transfecting HEK293T cells (ATCC® CRL-3216 ${ }^{\mathrm{TM}}$ ) with the transfer vector, psPAX2 packaging plasmid (Addgene \#12260) and the 427 pVSV envelope plasmid (Addgene \#8454) in proportion 5:4:1 using Lipofectamine ${ }^{\mathrm{TM}} 2000$ 428 (Themofisher) reagent according to manufacturer protocol. Standard DMEM (GIBCO) medium supplemented with 10\% Fetal bovine serum (FBS, Gibco) and $100 \mathrm{U} / \mathrm{mL}$ of penicillinStreptomycin (Gibco) was used for growing HEK293T cells and for lentivirus production. One $10 \mathrm{~cm}$ plate of HEK293T cells at 70-80\% confluency was used for the transfection. The medium was replaced 8 hours post-transfection. After 48 hours the medium containing viral particles was collected and filtered through a $0.45 \mu \mathrm{m}$ PES filter. The supernatant was directly used for 434 transfection or stored at $-80^{\circ} \mathrm{C}$. A 6 -well plate of $\mathrm{HCT} 116 \mathrm{cas} 9$ cells at $80 \%$ confluency was 435 transduced using $600 \mu \mathrm{L}$ of lentiviral supernatant $(300 \mu \mathrm{L}$ of each lentivirus produced for each 436 duplexes) supplemented with $4 \mu \mathrm{g} / \mathrm{mL}$ polybrene (Sigma) for 6 hours. The transduction media 437 was then changed with fresh DMEM for 24 hours then the transduced cells were selected using 438 DMEM containing $10 \mu \mathrm{g} / \mathrm{mL}$ Blasticidin (Invivogen) and $1 \mu \mathrm{g} / \mathrm{mL}$ Puromycin (Invivogen). 439 Genomic DNA was isolated from individual colonies and KO clones were screened by PCR 440 (primers in Table S1). The expected WT band for SLC35B2 is 469 bp and the mutant band 132 441 bp. For B4GALT7, the WT band is $341 \mathrm{bp}$ and mutant band $180 \mathrm{bp}$. For laboratory purposes, 
442 the SLC35B2 clones have been generated into HCT116cas9 cells that are expressing mCherry

443 and Citrine due to integration of miReporter-PGK (Addgene\#82477).

\section{Nucleic acids delivery}

446 Transfection using lipofectamine2000 (InvitroGen - 11668019) were performed following 447 manufacturer's instructions. For nucleofection, cells were nucleofected using Nucleofector SE 448 solution and reagent into Nucleocuvette following manufacturer's instructions using 4D449 Nucleofector System (Lonza). The cell number and nucleic acid amounts are indicated in each 450 figure legends. P-EGFP-N1 (Addgene plasmid\#2491) was used in transfection and 451 nucleofection experiments as a control.

452

453 Viability assay

454 PrestoBlue (PB) reagent (ThermoFisher - A13261) was used for viability assay according to 455 the manufacturer's protocol. After 24 to 48 hours post treatment (SINV, dsRNA 456 transfection/nucleofection), cells were incubated with PB reagent and cell viability was 457 assessed by measuring the fluorescence (excitation $570 \mathrm{~nm}$; emission $590 \mathrm{~nm}$ ) after 20 mins 458 incubation using SAFAS spectrofluorometer (Xenius XC). Cell viability was expressed as a 459 percentage relative to untreated cells.

461 Heparinase \& sodium chlorate treatment and heparan sulfate staining

462 Heparinase: $1.10^{6}$ were treated with $2 \mathrm{U}$ of Heparinase I and III blend from Flavobacterium 463 heparinum (Merck - H3917) for $1 \mathrm{~h}$ at $37^{\circ} \mathrm{C} 5 \% \mathrm{CO} 2$ in DMEM and then cells were reverse 464 transfected with $2 \mu \mathrm{g}$ of GFP using lipofectamine2000 (Invitrogen) in 6 well plate. 
465 Sodium chlorate: HCT116cas9 cells grow in $50 \mathrm{mM}$ sodium chlorate (Merck - 1.06420)

466 DMEM $10 \%$ FBS for at least $48 \mathrm{~h}$ then 150000 cells were reverse transfected with $500 \mathrm{ng}$ of 467 GFP using lipofectamine 2000 (Invitrogen) in 24 well plate.

46824 (heparinase) or 48 (sodium chlorate) hours post treatment, cells were detach using PBS $4690.02 \%$ EDTA, then heparan sulfate was stained using 1:30 of F58-10E4 as primary antibody 470 (AMSBIO, cat\#370255-S) in PBS 3\% BSA for 30 to 40 minutes on ice then washed with PBS

1\% FBS and incubated with 1:30 anti-mouse Alexa Fluor 594 (Thermo, A-11032) in PBS 3\%

BSA, washed twice using PBS 1\% FBS then and analysed on a FACSCalibur flow cytometer.

\section{dsRNA preparation}

475 PCR fragments corresponding to $231 \mathrm{nts}$ of the Citrine coding sequence were amplified from ES-FUCCI plasmid (Addgene plasmid\#62451) using primers containing T7 promoter sequence

with 2 distinct PCR fragment allowing the positive-sense or negative-sense RNA. Primers used to generate the PCR products are listed in Table S1. The PCR fragments were produced using DyNAzyme EXT DNA Polymerase (F-505S - Thermo Scientific) and purified using Monarch DNA extraction (T1020L - New England Biolab). In vitro transcription (IVT) with homemade

484 Scientific) for $30 \mathrm{~min}$ at $37^{\circ} \mathrm{C}$ and IVT product was purified, unincorporated nucleotides 485 removed and size checked using UV shadow (8\% acrylamide-urea gel) followed by phenol486 chloroform extraction and nanodrop quantification for each strand. We then mix an equal 487 quantity of positive-strand and negative-strand RNA, heat for $5^{\prime}$ at $95^{\circ} \mathrm{C}$ followed by slow cool 488 down to RT. The integrity of dsRNA is then checked by RNases T1 (EN0541 - Thermo 489 Scientific) and V1 (AM2275, Ambion) digestion. 


\section{Microscopy}

491 Imaging of cells treated with dsRNA/GFP plasmid was carried out on the Observer A1 (Zeiss)

492 microscope and analyzed using Fiji (46). Images of cells transfected with Poly(I:C) (LMW)

493 Rhodamine (tlrl-piwr - Invivogen $)(1,8 \mu \mathrm{g} / \mathrm{mL}, 24 \mathrm{~h}$ post plating of 76000 cells) into Lab-Tek

494 on glass coverslip (155411- Thermo Scientific) were acquired using a 100x Plan Apochromat 495 oil immersion NA1.4 objective on a spinning disk system Axio Observer Z1 (Zeiss) every 20 496 minutes for 72 hours. All pictures were acquired under the same conditions (laser power and 497 amplification gain) then processed with Fiji. Images of cells infected with SINV stained with $498 \mathrm{~J} 2$ antibody were carried out on BX51 microscope (Olympus).

499

$500 \quad$ FACS analysis

501 The cells intended for analysis by flow cytometry are recovered mechanically (PBS $0.5 \mathrm{mM}$ 502 EDTA) or using trypsin, washed in PBS and then suspended in PBS $1 \%$ FBS. Each acquisition 503 includes at least 10,000 events and is performed on the FACScalibur (BD Bioscience) device. 504 The data produced is processed using FlowJo software (FlowJo LLC).

505

\section{RT-qPCR analysis}

507 Total RNA was isolated using TRIzol (Invitrogen - 15596026) following manufacturer's 508 instructions. $1 \mu \mathrm{g}$ of RNA was reverse transcribed using SuperScript IV Vilo (Invitrogen 509 11756050) according to manufacturer's instructions. Real-time PCR was performed using 510 SYBR Green (Applied Biosystem - 4309155) and primers listed in Table S1 at an annealing 511 temperature of $60^{\circ} \mathrm{C}$ on a CFX96 thermal cycler (Biorad). Generated data were analysed using 512 the CFX Manager Software (Biorad).

\section{Western blot analysis}


515 Proteins were extracted using RIPA lysis buffer. Proteins were quantified by the Bradford

516 method and 20 to $30 \mu \mathrm{g}$ of total protein extract was loaded on $4-20 \%$ Mini-PROTEAN®

517 TGX ${ }^{\mathrm{TM}}$ Precast Gels (Biorad). After transfer onto nitrocellulose membrane, equal loading was

518 verified by Ponceau staining. Membranes were blocked in 5\% milk and probed with the 519 following antibodies: anti-Flag M2 (SIGMA, \#F1804) and anti-GAPDH (clone 6C5, BioRad \# 520 MCA4739P). Detection was performed using Chemiluminescent Substrate (Thermo Fisher).

\section{Data availability}

523 The CRISPR-Cas9 screen sequencing data discussed in this manuscript has been deposited on 524 NCBI's Sequence Read Archive (SRA) and has been attributed the BioProject ID 525 PRJNA662202. It can be accessed at the following URL: 526 https://submit.ncbi.nlm.nih.gov/subs/bioproject/SUB8109948/overview

\section{Acknowledgments}

529 The authors would like to thank members of the Pfeffer laboratory for discussion, Delphine

530 Richer for technical help, Dr. Jean-Daniel Fauny for help with the spinning disk microscope and Dr. Frédéric Gros for help with FACS analysis, Dr Carla Saleh for providing us the SINV WT and GFP clones.

533 This work was funded by the European Research Council (ERC-CoG-647455 RegulRNA) and 534 was performed under the framework of the LABEX: ANR-10-LABX-0036_NETRNA, which 535 benefits from a funding from the state managed by the French National Research Agency as 536 part of the Investments for the future program. This work has also received funding from the 537 People Programme (Marie Curie Actions) of the European Union's Seventh Framework 538 Program (FP7/2007-2013) under REA grant agreement $\mathrm{n}^{\circ}$ PCOFUND-GA-2013-609102, 539 through the PRESTIGE program coordinated by Campus France (to EG), and from the French 
540 Minister for Higher Education, Research and Innovation (PhD contract to OP). VL was

541 supported by the National Institutes of Health (R01GM083144). Sequencing was performed by

542 the GenomEast platform, a member of the 'France Génomique' consortium (ANR-10-INBS-

543 0009).

\section{Authors contribution}

546 SP and EG conceived the project. SP, EG and OP designed the work and analysed the results.

547 OP, EG, and RPN performed the experiments. EG and OP set up the CRISPR/Cas9 screens, 548 RPN generated the lentivirus library and the HCT16-Cas9 cell line. OP and RPN performed the 549 bioinformatics analysis of the screens. OP generated the SLC35B2 and B4GALT7 KO clones. 550 OP generated IVT dsRNA and perform validation of cell survival. EG produced SINV-GFP 551 viral stock, performed the infections and analysed viral titers. OP performed FACS analyses. 552 EG and OP performed the immunofluorescence assays. OP analysed the live-imaging 553 microscopy data. VL provided the COG KO cells and antibodies. OP, EG and SP wrote the 554 manuscript with input from the other authors. SP and EG coordinated the work. SP assured 555 funding. All authors reviewed the final manuscript. 


\section{References}

558

559

560

561

562

563

564

565

566

1. Bomsel M, Alfsen A. 2003. Entry of viruses through the epithelial barrier: pathogenic trickery. Nat Rev Mol Cell Biol 4:57-68.

2. Rusnati M, Vicenzi E, Donalisio M, Oreste P, Landolfo S, Lembo D. 2009. Sulfated K5 Escherichia coli polysaccharide derivatives: A novel class of candidate antiviral microbicides. Pharmacology \& Therapeutics 123:310-322.

3. Byrnes AP, Griffin DE. 1998. Binding of Sindbis virus to cell surface heparan sulfate. J Virol 72:7349-7356.

4. Smith TJ, Cheng RH, Olson NH, Peterson P, Chase E, Kuhn RJ, Baker TS. 1995. Putative receptor binding sites on alphaviruses as visualized by cryoelectron microscopy. Proc Natl Acad Sci USA 92:10648-10652.

5. Wahlberg JM, Bron R, Wilschut J, Garoff H. 1992. Membrane fusion of Semliki Forest virus involves homotrimers of the fusion protein. J Virol 66:7309-7318.

6. Weber F, Wagner V, Rasmussen SB, Hartmann R, Paludan SR. 2006. Double-Stranded RNA Is Produced by Positive-Strand RNA Viruses and DNA Viruses but Not in Detectable Amounts by Negative-Strand RNA Viruses. J Virol 80:5059-5064.

7. Schlee M, Hartmann G. 2016. Discriminating self from non-self in nucleic acid sensing. Nat Rev Immunol 16:566-580.

8. Stetson DB, Medzhitov R. 2006. Type I Interferons in Host Defense. Immunity 25:373381.

9. García MA, Meurs EF, Esteban M. 2007. The dsRNA protein kinase PKR: Virus and cell control. Biochimie 89:799-811.

10. Shalem O, Sanjana NE, Zhang F. 2015. High-throughput functional genomics using CRISPR-Cas9. Nat Rev Genet 16:299-311.

11. Han J, Perez JT, Chen C, Li Y, Benitez A, Kandasamy M, Lee Y, Andrade J, tenOever B, Manicassamy B. 2018. Genome-wide CRISPR/Cas9 Screen Identifies Host Factors Essential for Influenza Virus Replication. Cell Reports 23:596-607.

12. Park RJ, Wang T, Koundakjian D, Hultquist JF, Lamothe-Molina P, Monel B, Schumann K, Yu H, Krupzcak KM, Garcia-Beltran W, Piechocka-Trocha A, Krogan NJ, Marson A, Sabatini DM, Lander ES, Hacohen N, Walker BD. 2017. A genome-wide CRISPR screen identifies a restricted set of HIV host dependency factors. Nat Genet 49:193-203.

13. Zhang R, Miner JJ, Gorman MJ, Rausch K, Ramage H, White JP, Zuiani A, Zhang P, Fernandez E, Zhang Q, Dowd KA, Pierson TC, Cherry S, Diamond MS. 2016. A CRISPR 
screen defines a signal peptide processing pathway required by flaviviruses. Nature 535:164-168.

14. Golden RJ, Chen B, Li T, Braun J, Manjunath H, Chen X, Wu J, Schmid V, Chang T-C, Kopp F, Ramirez-Martinez A, Tagliabracci VS, Chen ZJ, Xie Y, Mendell JT. 2017. An Argonaute phosphorylation cycle promotes microRNA-mediated silencing. Nature 542:197-202.

15. Doench JG, Fusi N, Sullender M, Hegde M, Vaimberg EW, Donovan KF, Smith I, Tothova Z, Wilen C, Orchard R, Virgin HW, Listgarten J, Root DE. 2016. Optimized sgRNA design to maximize activity and minimize off-target effects of CRISPR-Cas9. Nat Biotechnol 34:184-191.

16. Li W, Xu H, Xiao T, Cong L, Love MI, Zhang F, Irizarry RA, Liu JS, Brown M, Liu XS. 2014. MAGeCK enables robust identification of essential genes from genome-scale CRISPR/Cas9 knockout screens. Genome Biol 15:554.

17. Li J-P, Kusche-Gullberg M. 2016. Heparan Sulfate: Biosynthesis, Structure, and Function, p. 215-273. In International Review of Cell and Molecular Biology. Elsevier.

18. Bishop JR, Schuksz M, Esko JD. 2007. Heparan sulfate proteoglycans fine-tune mammalian physiology. Nature 446:1030-1037.

19. Cagno V, Tseligka ED, Jones ST, Tapparel C. 2019. Heparan Sulfate Proteoglycans and Viral Attachment: True Receptors or Adaptation Bias? Viruses 11.

20. Lindahl U, Couchman J, Kimata K, Esko JD. 2015. Proteoglycans and Sulfated Glycosaminoglycans, p. . In Varki, A, Cummings, RD, Esko, JD, Stanley, P, Hart, GW, Aebi, M, Darvill, AG, Kinoshita, T, Packer, NH, Prestegard, JH, Schnaar, RL, Seeberger, PH (eds.), Essentials of Glycobiology, 3rd ed. Cold Spring Harbor Laboratory Press, Cold Spring Harbor (NY).

21. Safaiyan F, Kolset SO, Prydz K, Gottfridsson E, Lindahl U, Salmivirta M. 1999. Selective Effects of Sodium Chlorate Treatment on the Sulfation of Heparan Sulfate. J Biol Chem 274:36267-36273.

22. Blackburn JB, D'Souza Z, Lupashin VV. 2019. Maintaining order: COG complex controls Golgi trafficking, processing, and sorting. FEBS Lett 593:2466-2487.

23. Willett R, Ungar D, Lupashin V. 2013. The Golgi puppet master: COG complex at center stage of membrane trafficking interactions. Histochem Cell Biol 140:271-283.

24. Kranz C, Ng BG, Sun L, Sharma V, Eklund EA, Miura Y, Ungar D, Lupashin V, Winkel RD, Cipollo JF, Costello CE, Loh E, Hong W, Freeze HH. 2007. COG8 deficiency causes 
new congenital disorder of glycosylation type IIh. Human Molecular Genetics 16:731741.

25. Reynders E, Foulquier F, Leão Teles E, Quelhas D, Morelle W, Rabouille C, Annaert W, Matthijs G. 2009. Golgi function and dysfunction in the first COG4-deficient CDG type II patient. Human Molecular Genetics 18:3244-3256.

26. Spaapen LJM, Bakker JA, van der Meer SB, Sijstermans HJ, Steet RA, Wevers RA, Jaeken J. 2005. Clinical and biochemical presentation of siblings with COG-7 deficiency, a lethal multiple O- and N-glycosylation disorder. J Inherit Metab Dis 28:707-714.

27. Zeevaert R, Foulquier F, Jaeken J, Matthijs G. 2008. Deficiencies in subunits of the Conserved Oligomeric Golgi (COG) complex define a novel group of Congenital Disorders of Glycosylation. Molecular Genetics and Metabolism 93:15-21.

28. Shestakova A, Zolov S, Lupashin V. 2006. COG Complex-Mediated Recycling of Golgi Glycosyltransferases is Essential for Normal Protein Glycosylation: COG Complex and Golgi Glycosylation. Traffic 7:191-204.

29. Zolov SN, Lupashin VV. 2005. Cog3p depletion blocks vesicle-mediated Golgi retrograde trafficking in HeLa cells. J Cell Biol 168:747-759.

30. Bailey Blackburn J, Pokrovskaya I, Fisher P, Ungar D, Lupashin VV. 2016. COG Complex Complexities: Detailed Characterization of a Complete Set of HEK293T Cells Lacking Individual COG Subunits. Front Cell Dev Biol 4.

31. Strauss JH, Strauss EG. 1994. The alphaviruses: gene expression, replication, and evolution. Microbiol Rev 58:491-562.

32. Li Y, Muffat J, Omer Javed A, Keys HR, Lungjangwa T, Bosch I, Khan M, Virgilio MC, Gehrke L, Sabatini DM, Jaenisch R. 2019. Genome-wide CRISPR screen for Zika virus resistance in human neural cells. Proc Natl Acad Sci USA 116:9527-9532.

33. Tanaka A, Tumkosit U, Nakamura S, Motooka D, Kishishita N, Priengprom T, Sangasang A, Kinoshita T, Takeda N, Maeda Y. 2017. Genome-Wide Screening Uncovers the Significance of N-Sulfation of Heparan Sulfate as a Host Cell Factor for Chikungunya Virus Infection. J Virol 91:e00432-17, /jvi/91/13/e00432-17.atom.

34. Savidis G, McDougall WM, Meraner P, Perreira JM, Portmann JM, Trincucci G, John SP, Aker AM, Renzette N, Robbins DR, Guo Z, Green S, Kowalik TF, Brass AL. 2016. Identification of Zika Virus and Dengue Virus Dependency Factors using Functional Genomics. Cell Rep 16:232-246. 
35. Klimstra WB, Ryman KD, Johnston RE. 1998. Adaptation of Sindbis Virus to BHK Cells Selects for Use of Heparan Sulfate as an Attachment Receptor. Journal of Virology 72:7357-7366.

36. Mislick KA, Baldeschwieler JD. 1996. Evidence for the role of proteoglycans in cationmediated gene transfer. Proceedings of the National Academy of Sciences 93:1234912354.

37. Payne CK, Jones SA, Chen C, Zhuang X. 2007. Internalization and Trafficking of Cell Surface Proteoglycans and Proteoglycan-Binding Ligands. Traffic 8:389-401.

38. Jae LT, Raaben M, Riemersma M, van Beusekom E, Blomen VA, Velds A, Kerkhoven RM, Carette JE, Topaloglu H, Meinecke P, Wessels MW, Lefeber DJ, Whelan SP, van Bokhoven H, Brummelkamp TR. 2013. Deciphering the Glycosylome of Dystroglycanopathies Using Haploid Screens for Lassa Virus Entry. Science 340:479483.

39. Blackburn JB, Kudlyk T, Pokrovskaya I, Lupashin VV. 2018. More than just sugars: Conserved oligomeric Golgi complex deficiency causes glycosylation-independent cellular defects. Traffic 19:463-480.

40. Ungar D, Oka T, Brittle EE, Vasile E, Lupashin VV, Chatterton JE, Heuser JE, Krieger M, Waters MG. 2002. Characterization of a mammalian Golgi-localized protein complex, $\mathrm{COG}$, that is required for normal Golgi morphology and function. The Journal of Cell Biology 157:405-415.

41. D’Souza Z, Blackburn JB, Kudlyk T, Pokrovskaya ID, Lupashin VV. 2019. Defects in COG-Mediated Golgi Trafficking Alter Endo-Lysosomal System in Human Cells. Front Cell Dev Biol 7:118.

42. Climer LK, Pokrovskaya ID, Blackburn JB, Lupashin VV. 2018. Membrane detachment is not essential for COG complex function. MBoC 29:964-974.

43. Blackburn JB, Lupashin VV. 2016. Creating Knockouts of Conserved Oligomeric Golgi Complex Subunits Using CRISPR-Mediated Gene Editing Paired with a Selection Strategy Based on Glycosylation Defects Associated with Impaired COG Complex Function, p. 145-161. In Brown, WJ (ed.), The Golgi Complex. Springer New York, New York, NY.

44. López P, Girardi E, Mounce BC, Weiss A, Chane-Woon-Ming B, Messmer M, Kaukinen P, Kopp A, Bortolamiol-Becet D, Fendri A, Vignuzzi M, Brino L, Pfeffer S. 2020. Highthroughput fluorescence-based screen identifies the neuronal microRNA miR-124 as a positive regulator of alphavirus infection. J Virol JVI.02145-19, jvi;JVI.02145-19v1. 
45. Boussif O, Lezoualc'h F, Zanta MA, Mergny MD, Scherman D, Demeneix B, Behr JP. 1995. A versatile vector for gene and oligonucleotide transfer into cells in culture and in vivo: polyethylenimine. Proc Natl Acad Sci USA 92:7297-7301.

692 46. Schindelin J, Arganda-Carreras I, Frise E, Kaynig V, Longair M, Pietzsch T, Preibisch S, 693 Rueden C, Saalfeld S, Schmid B, Tinevez J-Y, White DJ, Hartenstein V, Eliceiri K, 694 Tomancak P, Cardona A. 2012. Fiji: an open-source platform for biological-image 695 analysis. Nat Methods 9:676-682.

696 47. Sievers F, Wilm A, Dineen D, Gibson TJ, Karplus K, Li W, Lopez R, McWilliam H, 697 Remmert M, Söding J, Thompson JD, Higgins DG. 2011. Fast, scalable generation of high-quality protein multiple sequence alignments using Clustal Omega. Mol Syst Biol 699 7:539. 


\section{Figures legends}

702

703

704

705

706

707

708

709

710

711

712

713

714

715

716

717

718

719

720

721

722

723

724

725

Figure 1. CRISPR-Cas9 survival screen to long dsRNA identifies the extracellular heparan-sulfates as necessary for nucleic acids internalization and cell death induction.

A. Schematic representation of the CRISPR-Cas9 approach. HCT116 cells stably expressing a human codon-optimized $S$. pyogenes Cas9 protein were transduced with the lentiviral sgRNA library Brunello (MOI 0.3). $60.10^{6}$ cells transduced cells were selected with $1 \mu \mathrm{g} / \mathrm{mL}$ puromycin to obtain a mutant cell population to cover at least $300 \times$ the library. Selective pressure via synthetic long dsRNA $(1 \mu \mathrm{g} / \mathrm{mL})$ was applied to induce cell death (in red). DNA libraries from input cells and cells surviving the dsRNA treatment as three independent biological replicates were sequenced on an Illumina HiSeq4000. Comparison of the relative sgRNA boundance in the Input and dsRNA condition were done using the MAGeCK standard pipeline. B. Median normalized read count distribution of all sgRNAs for the Input (in black) and dsRNA (in red) replicates. C. Bubble plot of the candidate genes. Significance of RRA score was calculated for each gene in the dsRNA condition compared to INPUT using the MAGeCK software. The number of enriched sgRNAs for each gene is represented by the bubble size. The gene ontology pathways associated to the significant top hits are indicated in orange and green. D. Viability assay. Cells were transfected (80000 cells; $1 \mu \mathrm{g} / \mathrm{mL}$ ) or nucleofected (200000 cells; 400 ng) with synthetic long dsRNA and cell viability was quantified $24 \mathrm{~h}$ (nucleofection) or $48 \mathrm{~h}$ (transfection) post treatment using PrestoBlue reagent. Average of at least three independent biological experiments +/- SD is shown. One-way ANOVA analysis, ${ }^{*} \mathrm{p}<0.05$. E-F. Cy5-labeled dsRNA (80 000 cells; $1 \mu \mathrm{g} / \mathrm{mL}$ ) was transfected into HCT116cas9, B4GALT7\#1 and 2, SLC35B2\#1 and \#2 cells and Cy5 fluorescence was quantified using FACS (10 000 events). The relative number of the Cy5 positive (Cy5+) cells (E) and the relative median of Cy5 intensity of fluorescence (F) compared to HCT116cas9 cells are shown. Average of three independent biological experiments +/- SD are shown. Paired t.test 
analysis, $* \mathrm{p}<0.05$. G. Quantification of extracellular heparan-sulfates. FACS analysis of HCT116 control or KO clones stained with the HS-specific antibody 10E4 (in red) compared to unstained samples (in blue) (10 000 events). One representative experiment out of three is shown.

Figure 2. COG4 is a novel host susceptibility factor to long dsRNA induced cell death.

A. Viability assay. Cells (80 000 cells; $1 \mu \mathrm{g} / \mathrm{mL})$ were transfected with dsRNA then the viability of the cells was quantified 48 h post transfection using PrestoBlue reagent. Data from at least three independent biological experiments are shown. One-way ANOVA analysis, ${ }^{*} \mathrm{p}<$ and rescued cells. Cy5 fluorescence was quantified using FACSCalibur (10 000 events). The percentage of Cy5+ cells (B) and the relative median of Cy5 intensity of fluorescence $(\mathbf{C})$ compared to parental HEK293T cells is shown. Average of three experiments +/- SD are shown. extracted $24 \mathrm{~h}$ post transfection and quantified by RT-qPCR. The histogram represents the expression fold change of synthetic dsRNA (D) and IFN- $\beta$ mRNA (E) relative to GAPDH mRNA in dsRNA transfected HEK293T KO COG4 rescued compared to HEK293T KO COG4. Average of three independent biological experiments +/- SD are shown. Paired t.test analysis, $* \mathrm{p}<0.05$. F-G. poly I:C rhodamine transfection and immunofluorescence in HEK293T and HEK293T KO COG4. Cells were transfected with rhodamine-labeled poly I:C

747 (in red) and with a Rab5-GFP plasmid (in green). Images were acquired using a spinning disk 748 microscope at different time post transfection. Representative pictures (E) and the 749 approximative number of rhodamine-positive foci per cells quantified by counting 7 fields per 750 conditions $(\mathbf{F})$ are shown. Two-way ANOVA analysis, $* \mathrm{p}<0.05$ 
Figure 3. CRISPR-Cas9 screen identifies COG4 as a permissivity factor to SINV

A. Schematic representation of the CRISPR-Cas9 approach. HCT116 cells stably expressing a

library Brunello (MOI 0.3). $60.10^{6}$ transduced cells were selected with $1 \mu \mathrm{g} / \mathrm{mL}$ puromycin to and cells surviving the dsRNA treatment as three independent biological replicates were sequenced on an Illumina HiSeq4000. Comparison of the relative sgRNA boundance in the

760 Input and dsRNA condition were done using the MAGeCK standard pipeline

B. Median normalized read count distribution of all $\operatorname{sgRNAs}$ for the Input (in black) and SINV

762 (in red) replicates. C. Bubble plot of the candidate genes. Significance of RRA score was 763 calculated for each gene in the dsRNA condition compared to INPUT using the MAGeCK 764 software. The number of enriched sgRNAs for each gene is represented by the bubble size. The 765 gene ontology pathways associated to the significant top hits are indicated in orange and green.

766 D. Viability of cells upon SINV infection. Cells were infected with SINV at MOI of 0.1 then 767 the viability of the cells was quantified 24,48 and $72 \mathrm{~h}$ post infection using PrestoBlue reagent. 768 One-way ANOVA analysis, * $\mathrm{p}<0.05$. D. SINV-GFP plaque assay. WT, COG4KO and 769 rescued HEK293T cells were infected with SINV-GFP for 24 and $48 \mathrm{~h}$ at MOI of 1 and 770 supernatant was collected in order to measure viral production. The fold change in titer relative 771 to HEK293T arbitrarily set to 1 is shown. Average of three independent biological experiments $772+$ - SD is shown. Paired t.test analysis $* \mathrm{p}<0.05$. 


\section{Supplemental information}

\section{Supplemental figures legends}

778

779

780

781

782

783

784

785

786

787

Figure S1. Set up of the HCT116 cells as model for SINV infection and dsRNA-induced cell death.

A. Representative pictures of HCT116cas9 cells uninfected or infected with SINV-GFP MOI of 1 at 24 and $48 \mathrm{~h}$ post infection (hpi). $5 \times$ optical microscopy. B. Representative pictures of HCT116cas9 cells at 24 and 48h post dsRNA (80000 cells; $1 \mu \mathrm{g} / \mathrm{mL}$ ) compared to non transfected ones. 5X optical microscopy. C. Western blot of FLAG-Cas9 expression in HCT116cas9 cells. Antibody against FLAG and GAPDH (normalizer) were used. D-E. Distribution of sgRNA normalized read counts of selected genes. The read counts for the four individual sgRNAs targeting enriched (SLC35B2, BGAL4T7, COG4) and not enriched genes (DDX58, negative control) in the dsRNA samples (D) and in the SINV samples (E) over the Input are shown.

Figure S2. Generation of SLC35B2 and B4GALT7 HCT116 CRISPR/Cas9 knock-out monoclonal cell lines.

A. PCR screen of SLC35B2 and B4GALT7 knock-out clones obtained by CRISPR/Cas9. The gels show the amplicons corresponding to wild type and deleted alleles that were subsequently sequenced. B. Clustal Omega (47) alignment of the wild type and mutated peptide sequences corresponding to the genomic deletions identified in the different clones. The reference aminoacidic sequence is represented in yellow (unknown domains - InterPro) and orange (known domains - InterPro). The peptidic sequences resulting in shorter protein due to deletions or formation of premature stop codon in the knock-out clones are represented with black bars or red rectangles, respectively. 
Figure S3: GFP plasmid transfectability in SLC35B2 and B4GALT7 HCT116

803 A. Representative pictures of GFP plasmid transfectability assay. Cells were transfected

804 (80 000 cells; $2 \mu \mathrm{g} / \mathrm{mL}$ ) or nucleofected (200 000 cells; $500 \mathrm{ng}$ ) with a plasmid coding for GFP

805

806

807

808

809

810

811

812

813

814

815

816 and the GFP positive cells were observed by fluorescence microscopy at $24 \mathrm{~h}$ (nucleofection) or $48 \mathrm{~h}$ (transfection) post treatment. Pictures were taken at $10 \times$ magnification, scale bar represents $50 \mu \mathrm{m}$. B. GFP transfectability by FACS analysis. The different cell types were transfected (80 000 cells; $2 \mu \mathrm{g} / \mathrm{mL}$ ) with plasmid coding for GFP for $48 \mathrm{~h}$. The percentage of GFP+ cells were determined by FACS analysis using a FACSCalibur. C-D-E. DNA plasmid transfectability assay upon heparan-sulfates depletion. Cells were treated with $50 \mathrm{mM}$ sodium chlorate or with 2 units of heparinase then transfected with GFP plasmid. The relative number of GFP positive (GFP+) cells (C), the GFP intensity of fluorescence (D) and the relative median intensity of fluorescence of extracellular heparan-sulfates (HS) staining (E) were quantified 48h post transfection using FACS (10 000 events). Data from at least three independent biological experiments $+/-\mathrm{SD}$ are shown. Paired t.test analysis, ${ }^{*} \mathrm{p}<0.05$.

Figure S4. Characterization of the survival phenotype in HCT116 KO COG4 and HEK293 KO COG4 cells.

A. Viability assay. HCT116cas9 and HCT116cas9 KO COG4 cells (80 000 cells; $1 \mu \mathrm{g} / \mathrm{mL})$ were transfected with dsRNA then the cell viability was quantified $48 \mathrm{~h}$ post transfection using PrestoBlue reagent. Data from at least three independent biological experiments are shown. Paired t.test analysis, ${ }^{*} \mathrm{p}<0.05$. B-C. Cy5-labeled dsRNA transfection $(80000$ cells; $1 \mu \mathrm{g} / \mathrm{mL})$ in HCT116cas9 and HCT116cas9 KO COG4 cells. Cy5 fluorescence was quantified using FACSCalibur (10 000 events). The relative number of Cy5+ cells (B) and the relative median 
of Cy5 intensity of fluorescence (C) compared to parental HCT116cas9 cells is shown. Average extracellular heparan-sulfates. Upper panel correspond to FACS analysis of HEK293T control (WT \& rescued - respectively in red and orange) or HEK293T KO COG4 (in blue) cells stained with the HS-specific antibody 10E4 and lower panel show the unstained sample and HEK293T

830 KO COG4. One representative experiment out of three is shown. (10 000 events) E-F. GFP transfectability by FACS analysis. HEK293T and HEK293T KO COG4 cells were transfected (80 000 cells; $2 \mu \mathrm{g} / \mathrm{mL}$ ) with plasmid coding for GFP for $48 \mathrm{~h}$. The percentage of GFP+ cells

(E) and the relative median of GFP intensity of fluorescence (F) compared to parental HEK293T cells was determined by FACS analysis using a FACSCalibur. Average of three experiments +/- SD are shown Paired t.test analysis, ${ }^{*} \mathrm{p}<0.05$.

\section{Figure S5. Accumulation of GFP and dsRNA upon SINV infection in presence or absence} and stained with $\mathrm{J} 2$ antibody, which recognizes dsRNA longer than 40bp and DAPI to stain the nuclei. Pictures were taken at 40× magnification with BX51 (Olympus) microscope.

\section{Table S1}

846 List of primers used in the study.

\section{$847 \quad$ Dataset S1}

848 Count of sequenced sgRNA per genes in every replicates

\section{Dataset S2}


850 MAGeCK comparison report enriched sgRNAs in dsRNA versus Input samples

\section{$851 \quad$ Dataset S3}

852 MAGeCK comparison report enriched sgRNAs in SINV versus Input samples 
bioRxiv preprint doi: https://doi.org/10.1101/2020.05.20.105528; this version posted October 14, 2020. The copyright holder for this

preprint (which was not certified by peer review) is the author/funder. All rights reserved. No reuse allowed without permission.

A.

$\stackrel{\longrightarrow}{\longrightarrow}$ Puromycin selection
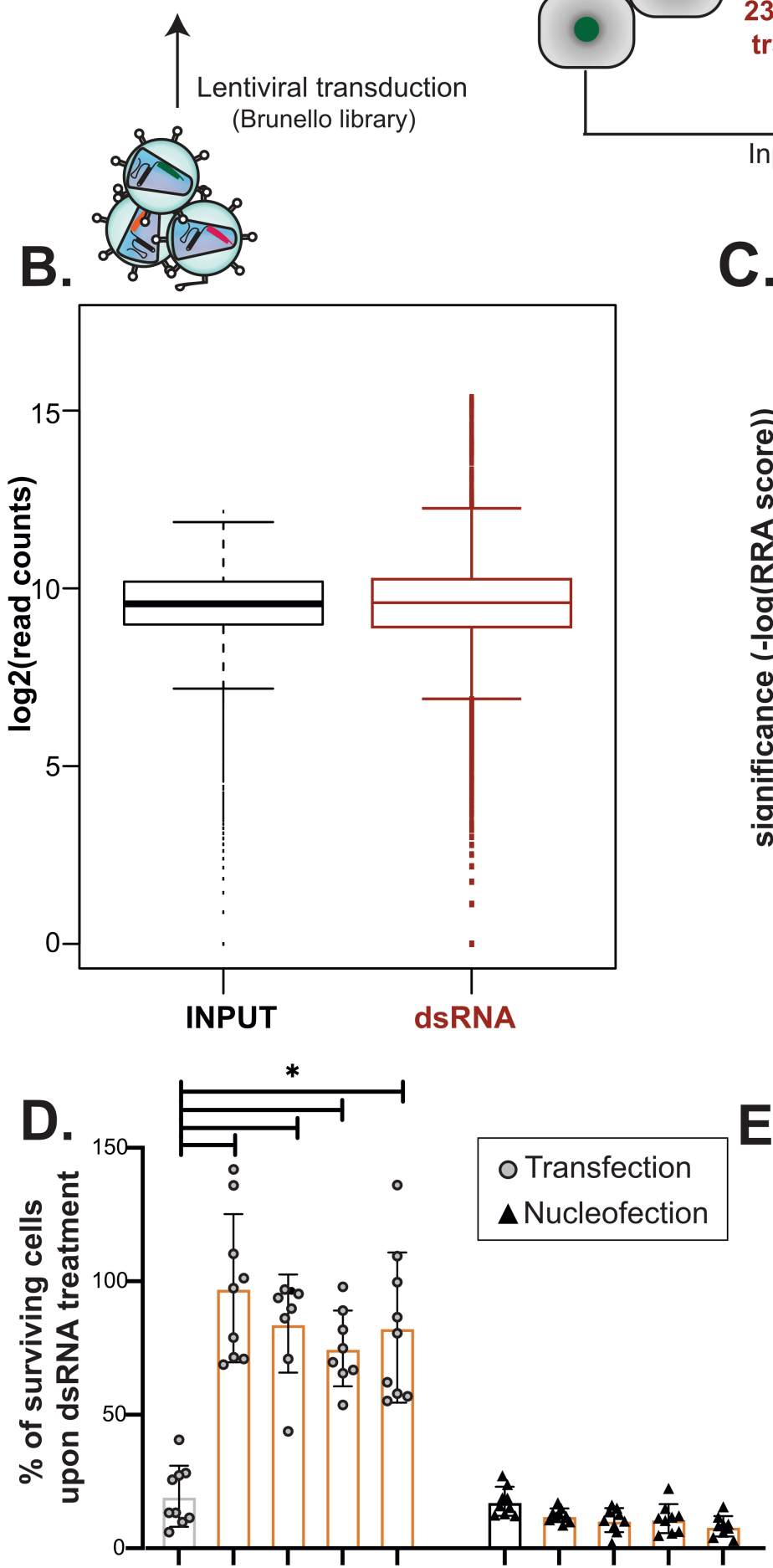

$5^{9} x^{2} x^{1} x^{2} \quad 2^{9} x^{2} x^{2} x^{2}$

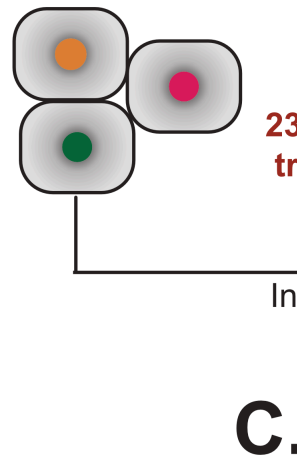

C.

E

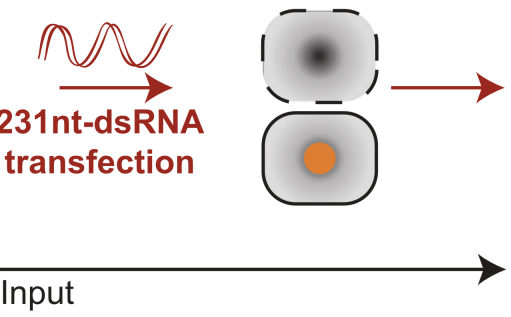

Library preparation

and comparison of

relative gRNA aboundance

I by high-throughput sequencing
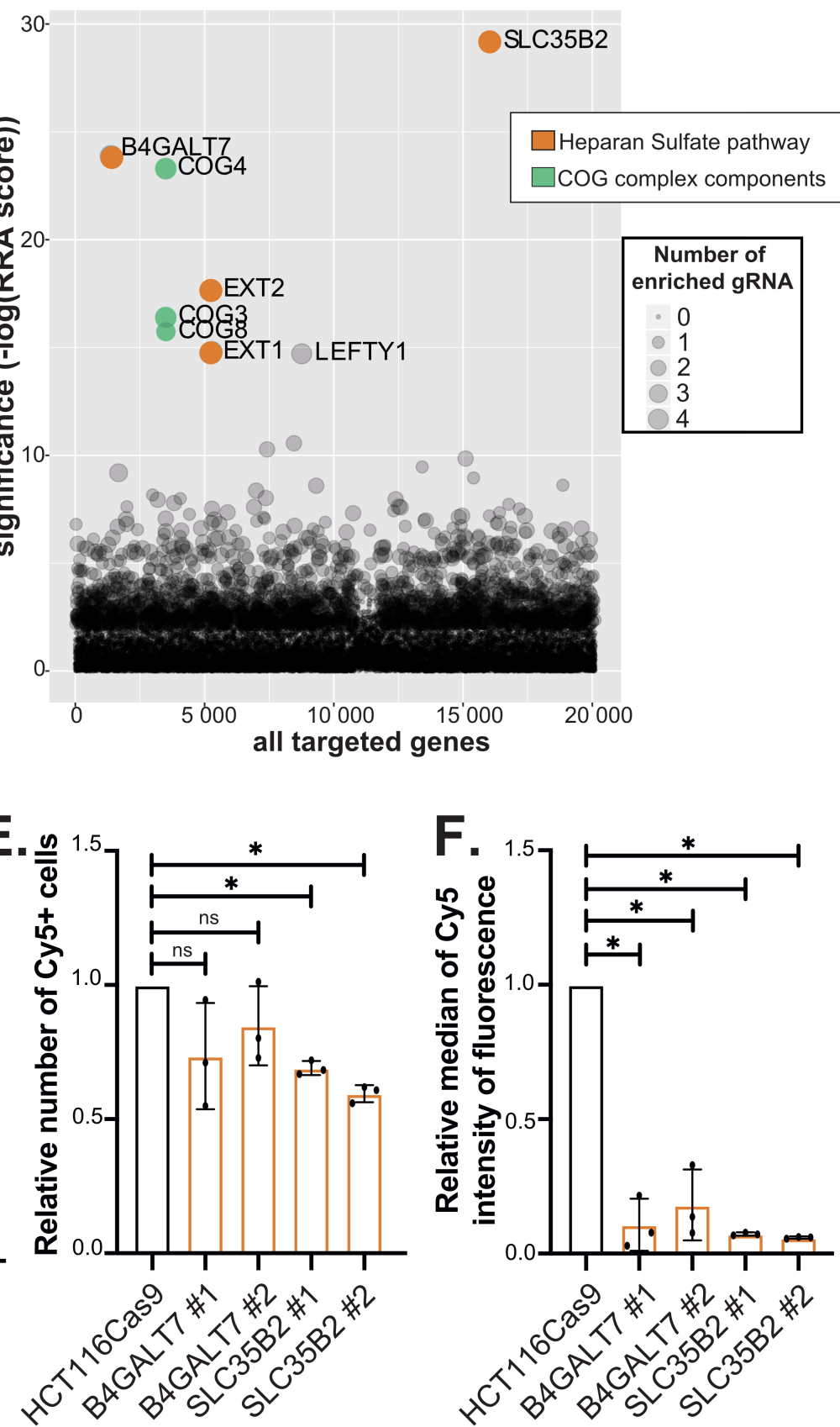

G.
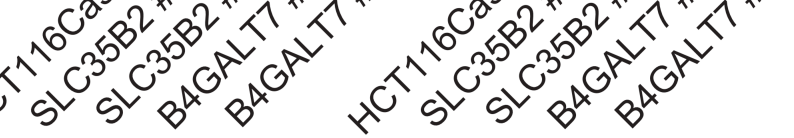

SLC35B2
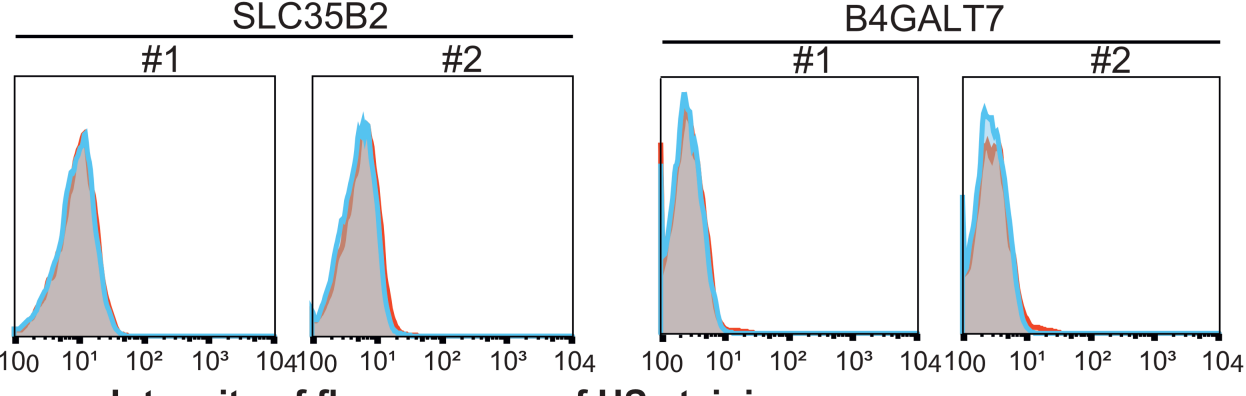

Intensity of fluorescence of HS staining 
A.
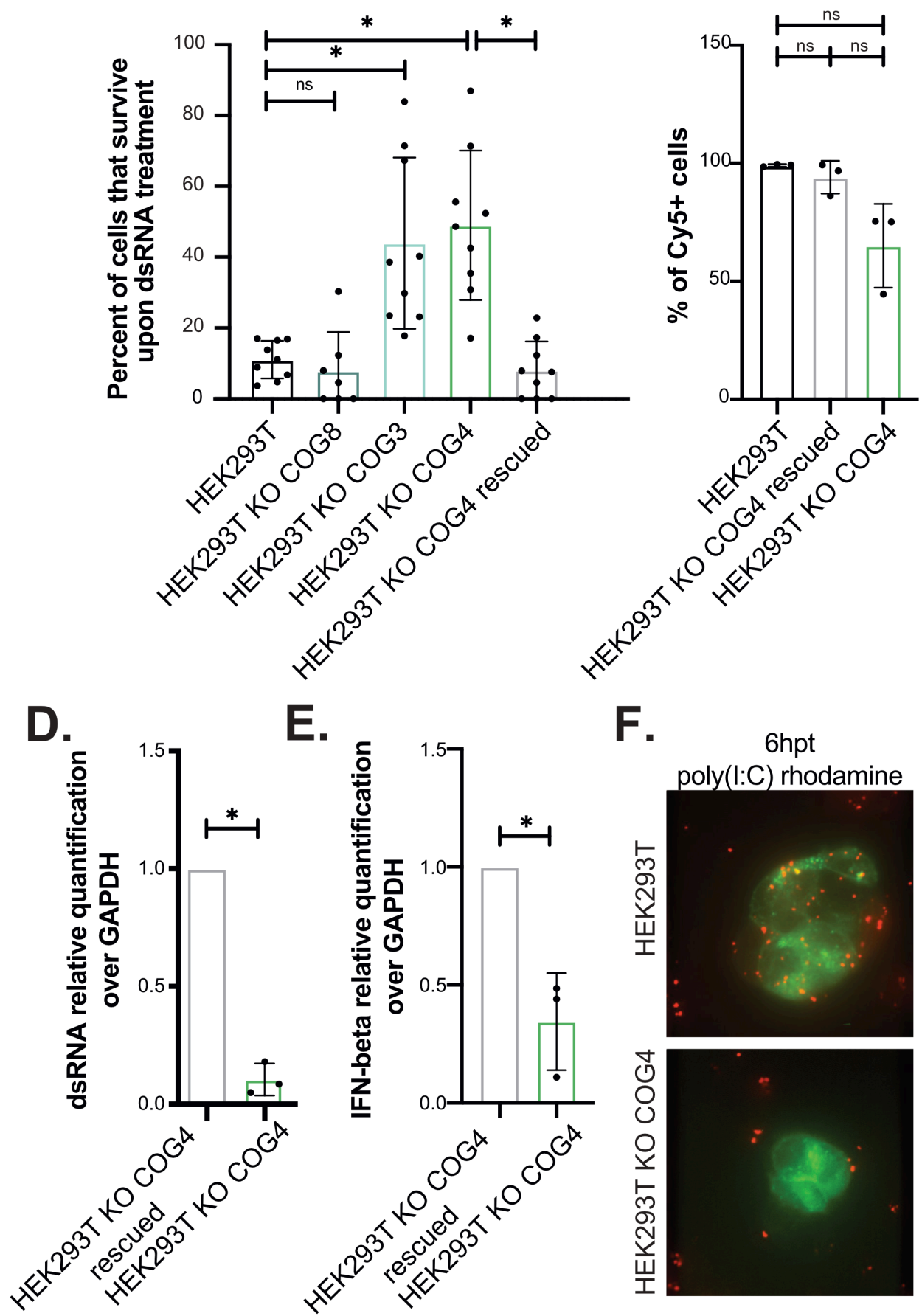

B.

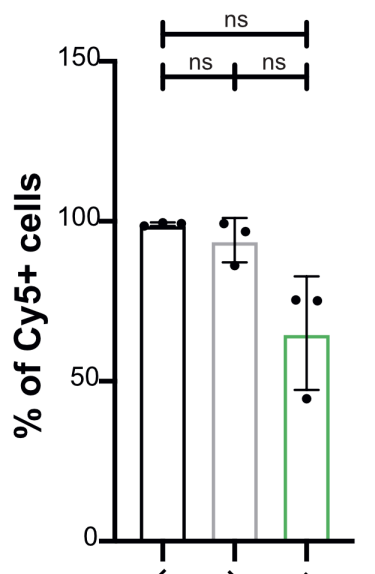

F.

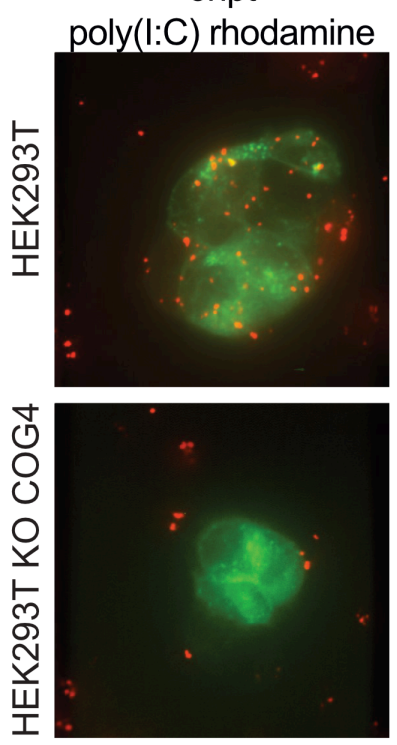

C.
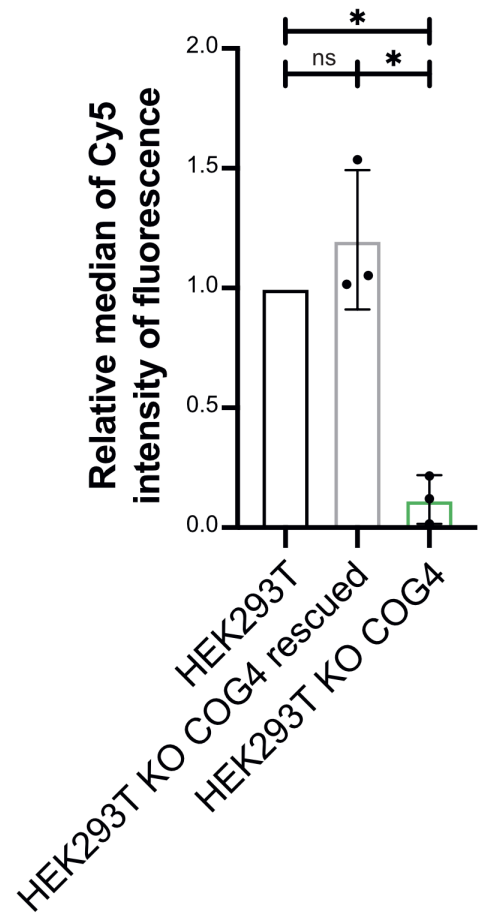

G.

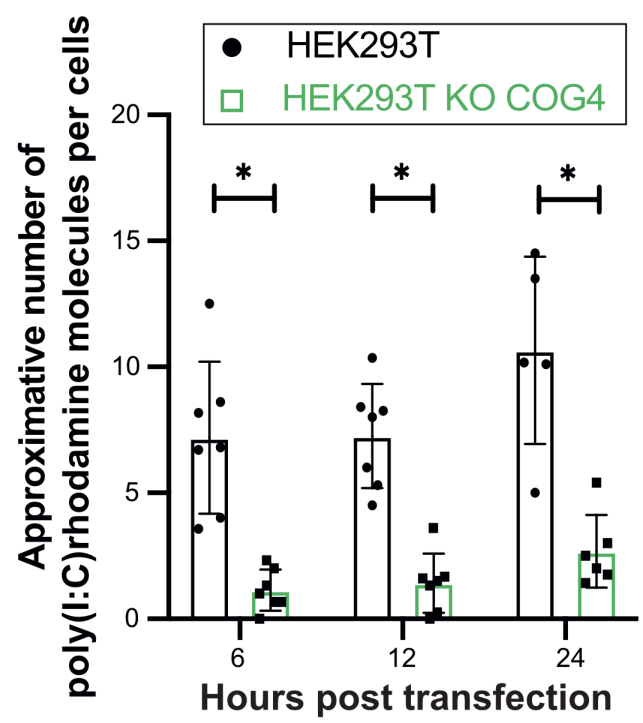

Figure 2 
A.

HCT116cas9 cells

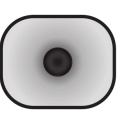

Puromycin selection

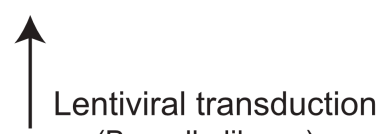
(Brunello library)

B.
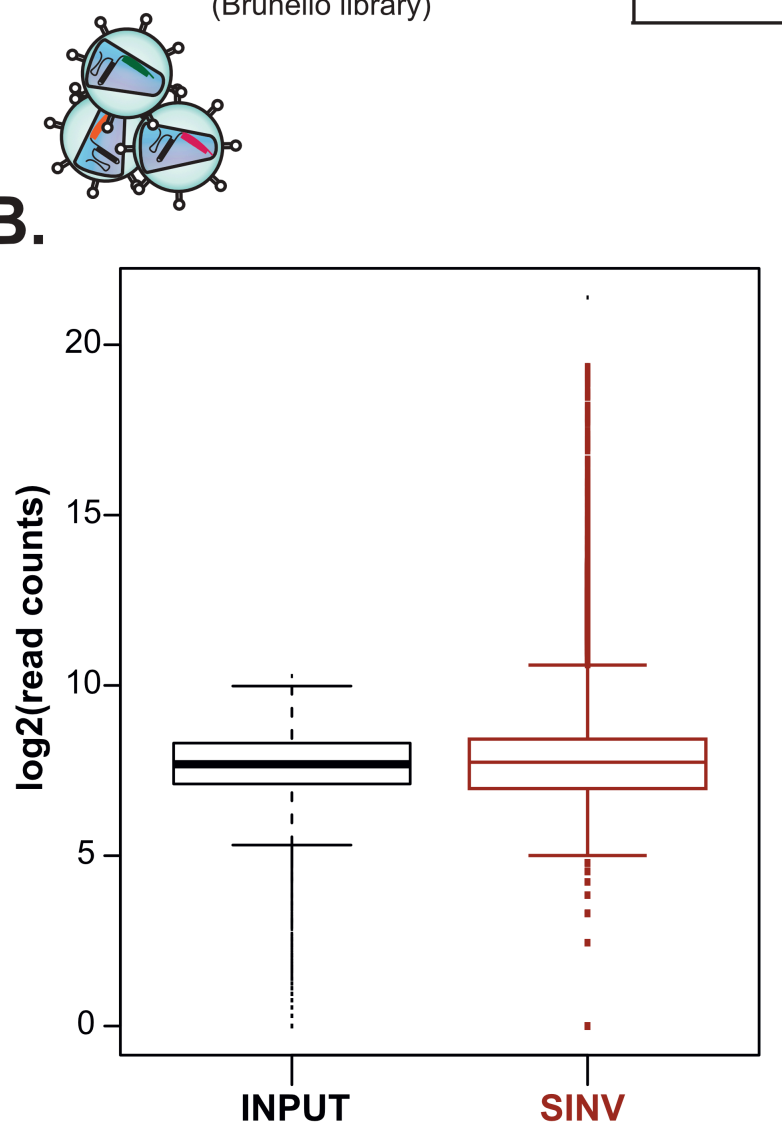

D.

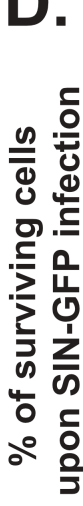

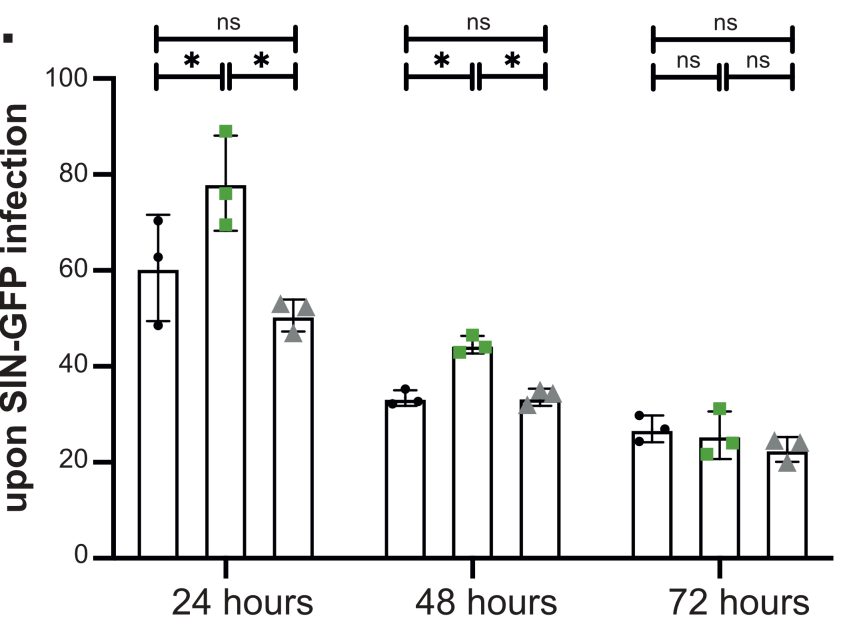

Pool transduced cells

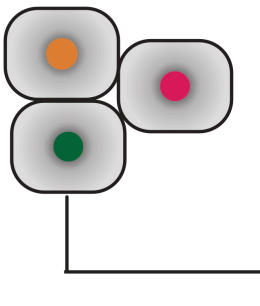

Input
Enriched mutants

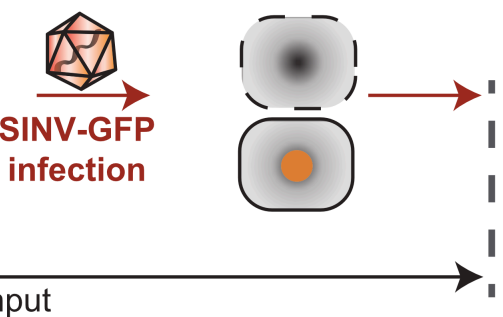

Library preparation and comparison of relative gRNA aboundance I by high-throughput sequencing
C.

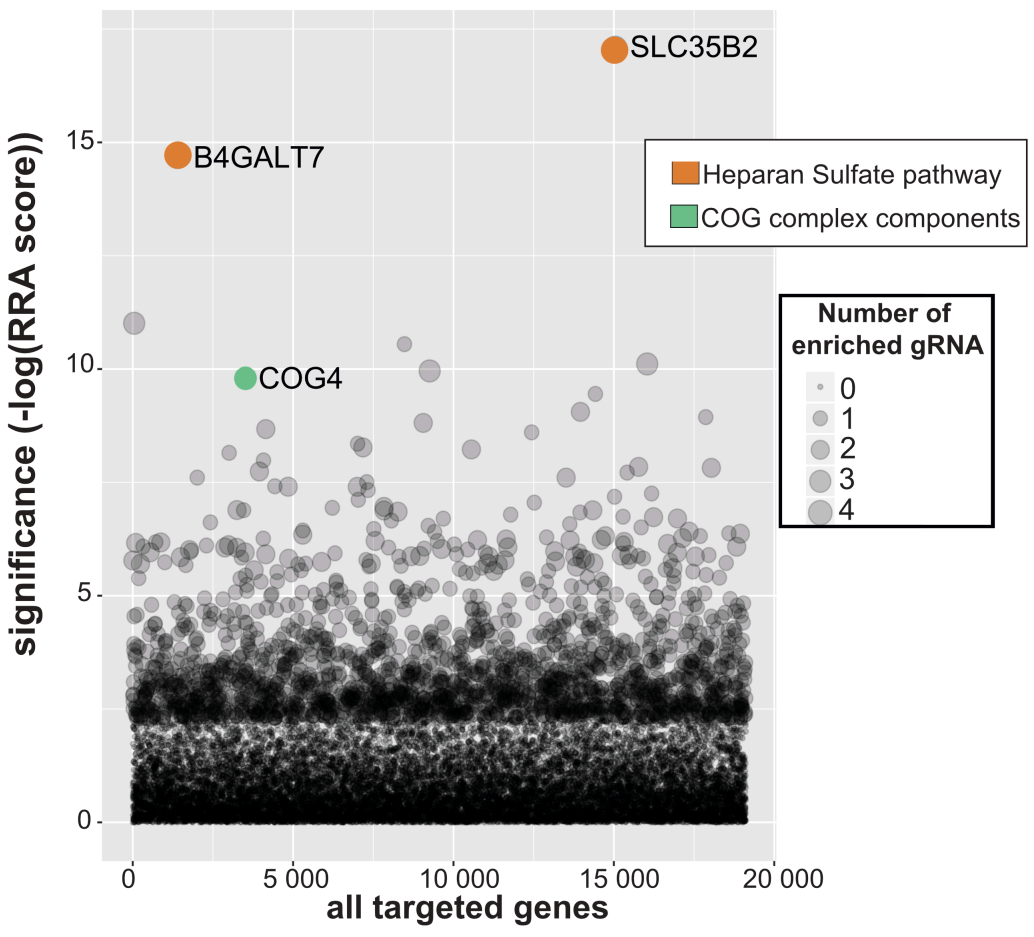

E.

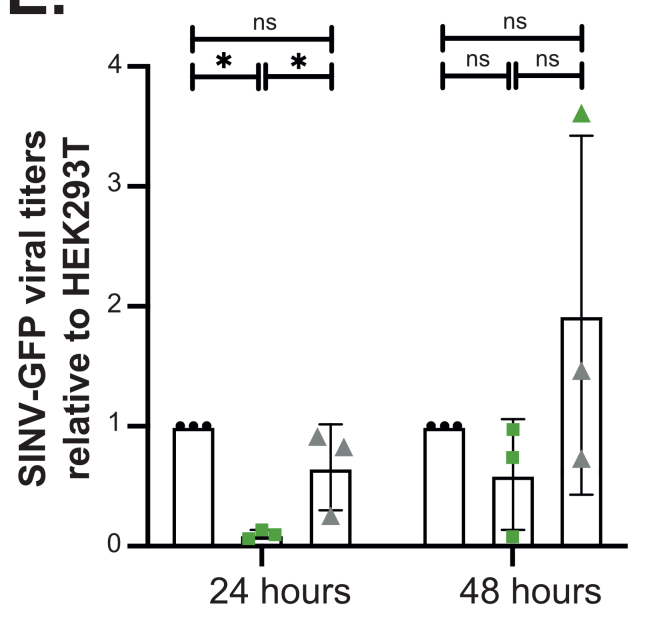

- HEK293T HEK293T KO COG4 $\triangle$ HEK KO COG4 rescued 

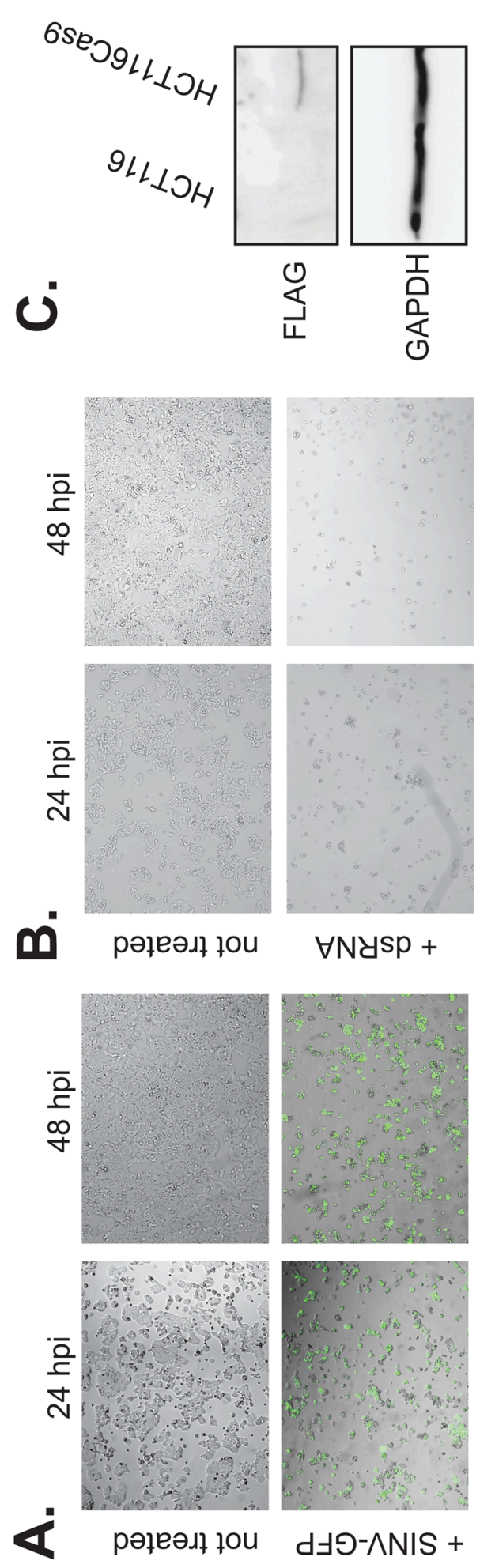
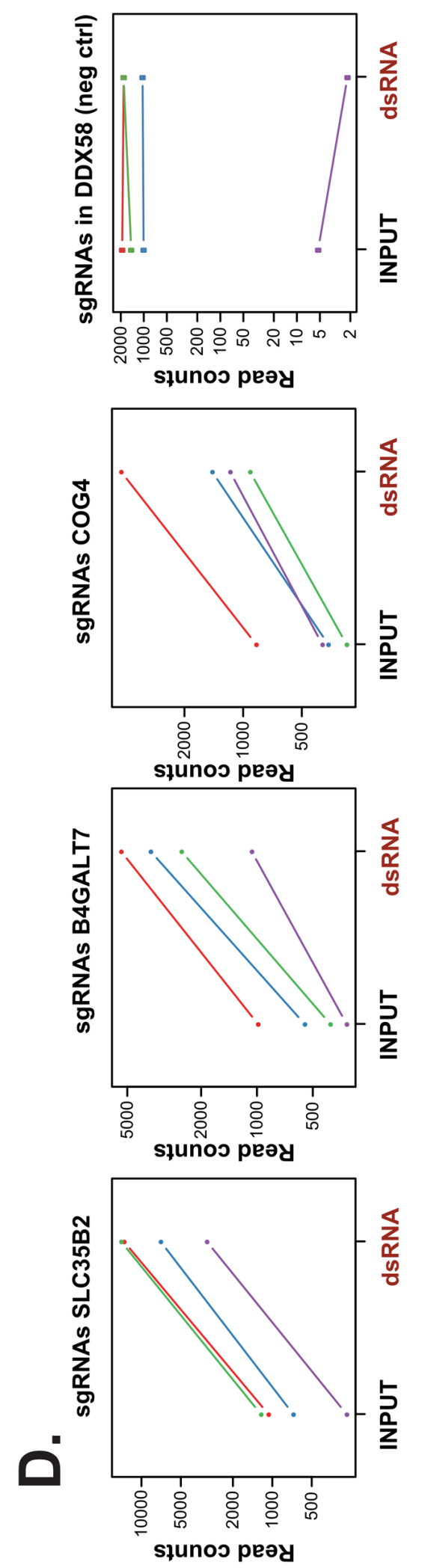
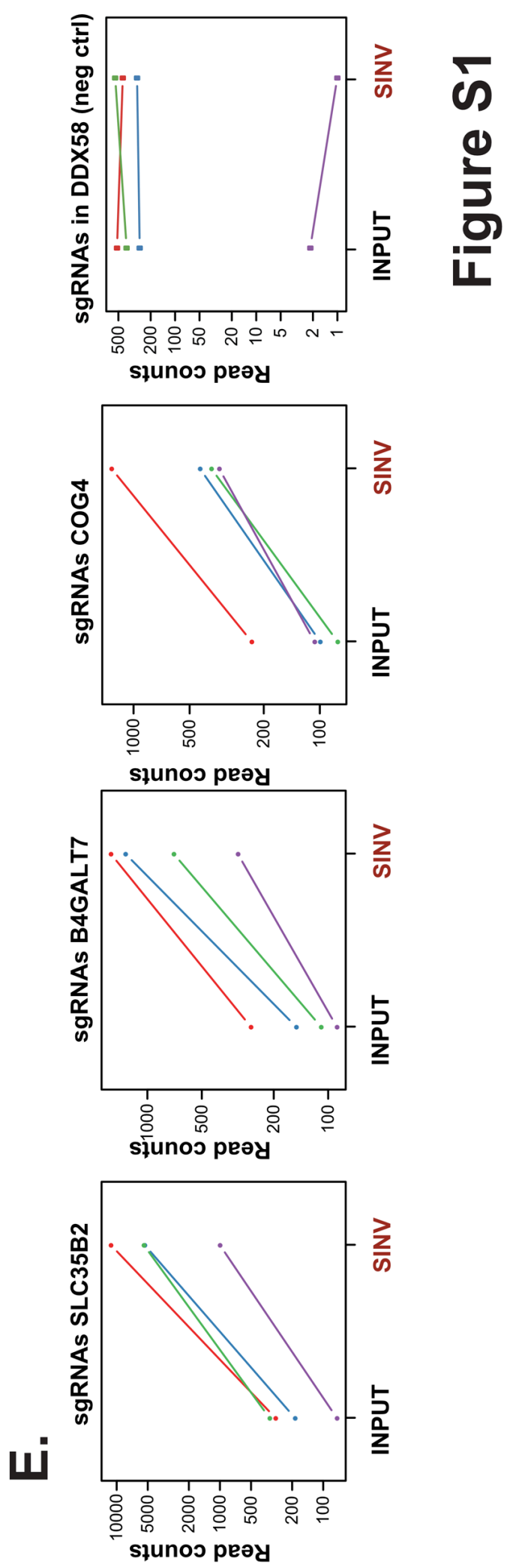
A.
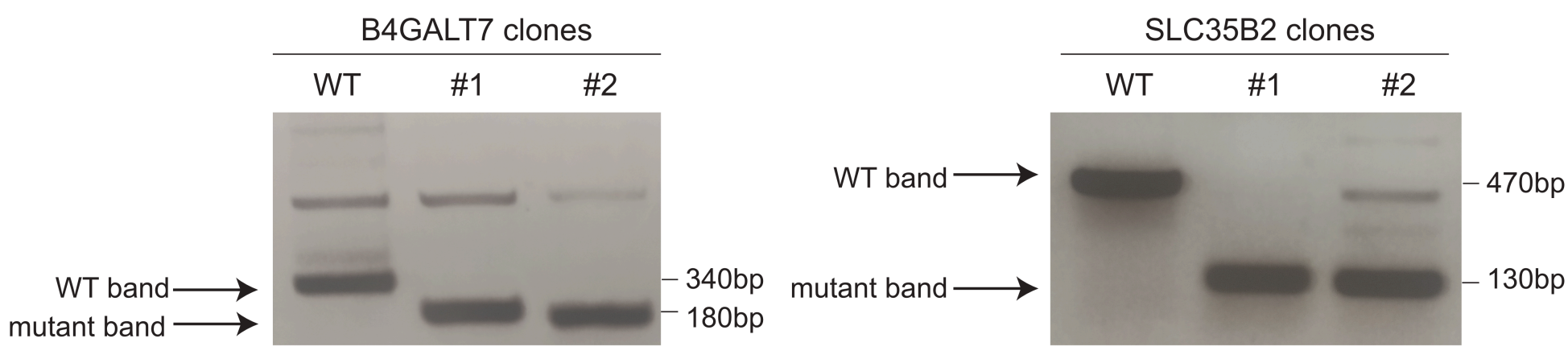

B.

\section{B4GALT7}

B4GALT7 wild type

B4GALT7 \#1

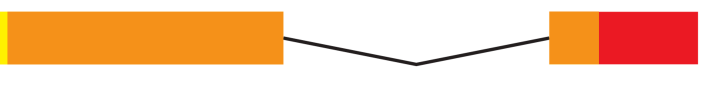

190

B4GALT7 \#2

\section{SLC35B2}

SLC35B2 wild type

SLC35B2 \#1 allele 1

domains (InterPro)

sequence identical to wild type

frameshift

deletion 
bioRxiv preprint doi: https://doi.org/10.1101/2020.05.20.105528; this version posted October 14,2020 . The copyright holder for this

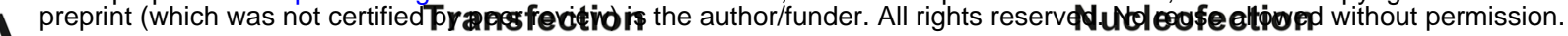

A.

HCT116cas9

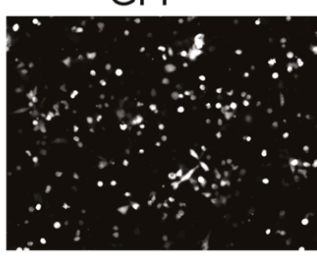

merge

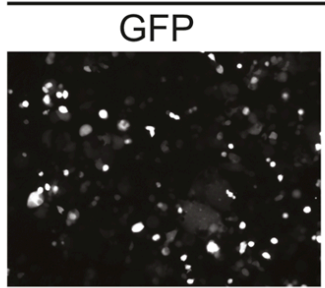

merge

SLC35B2 \#1
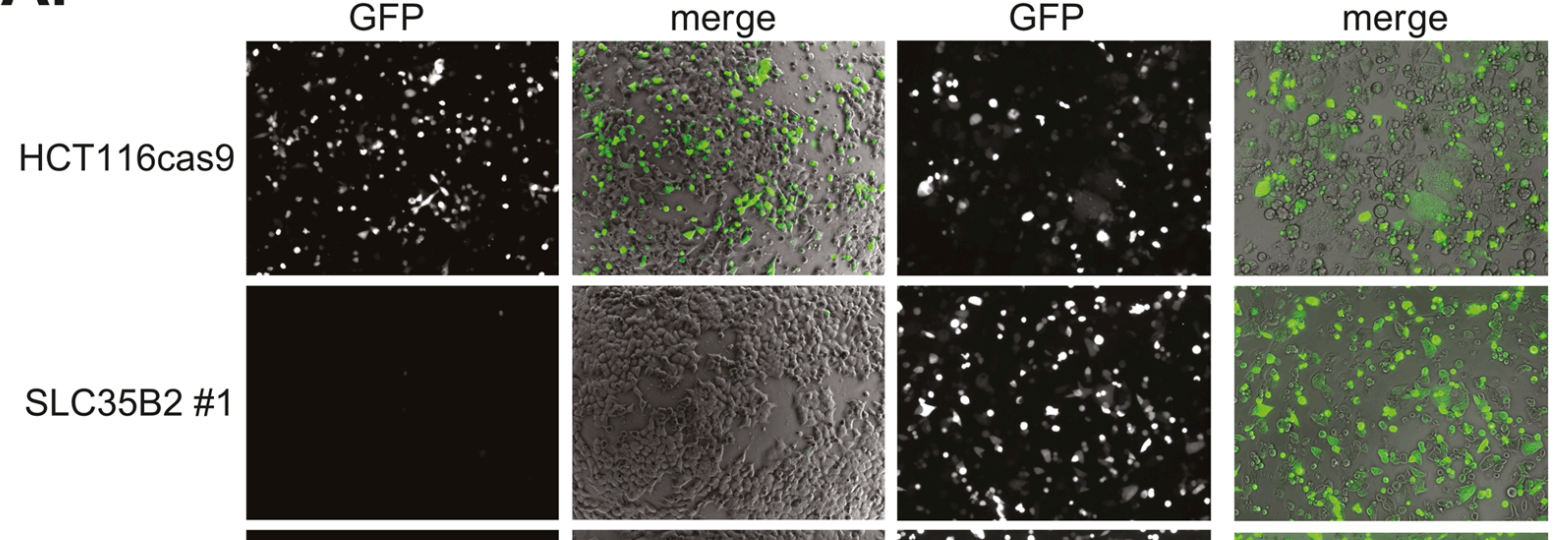

SLC35B2 \#2
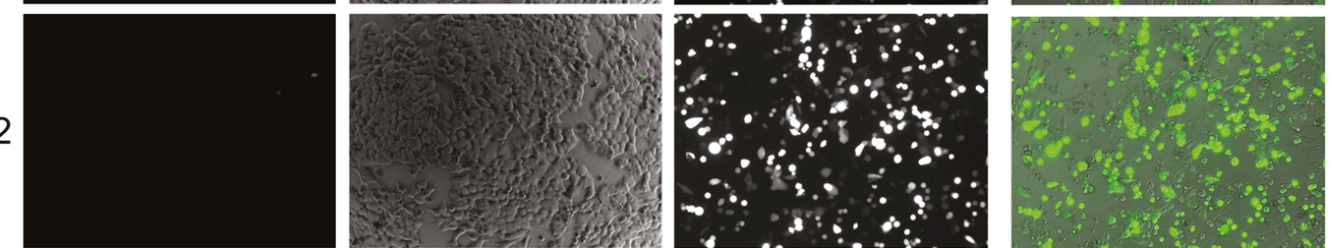

B4GALT7 \#1
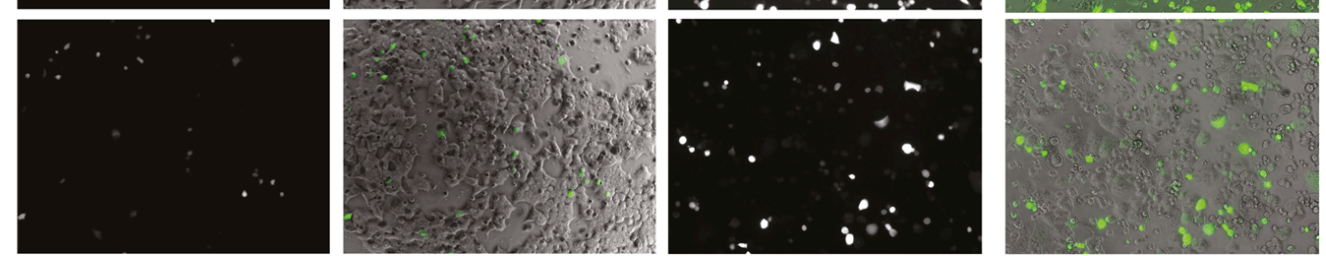

B4GALT7 \#2
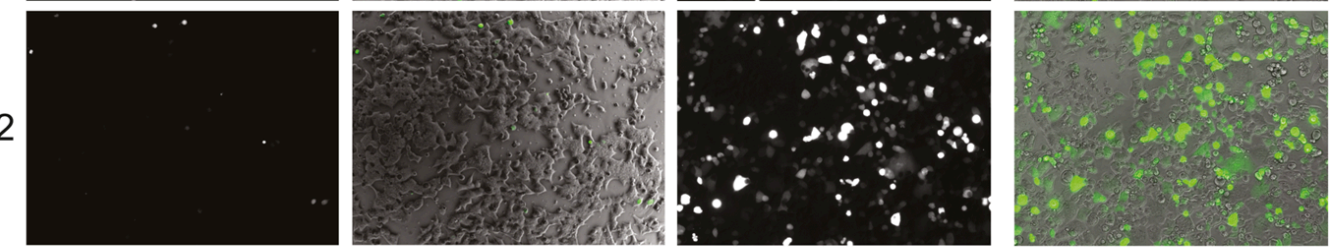

\section{B.}

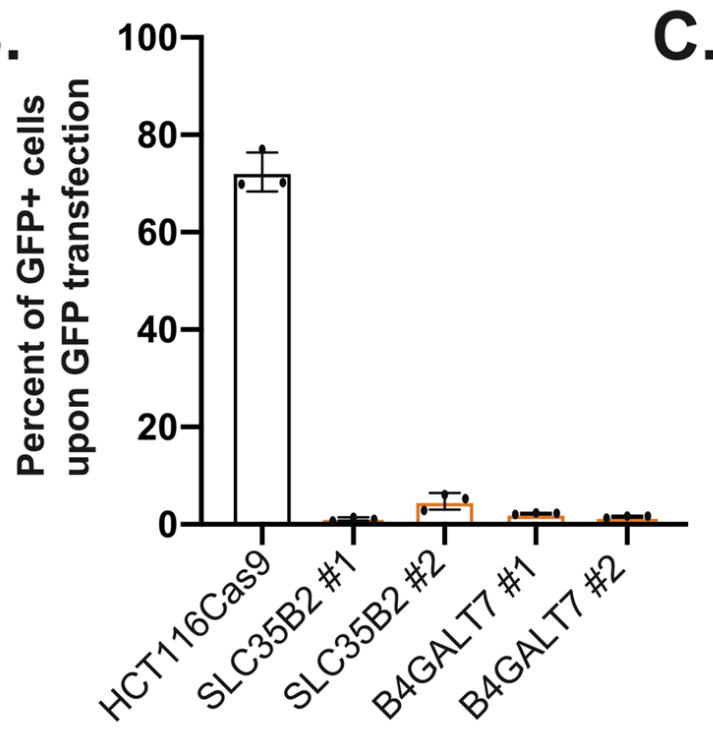

E.

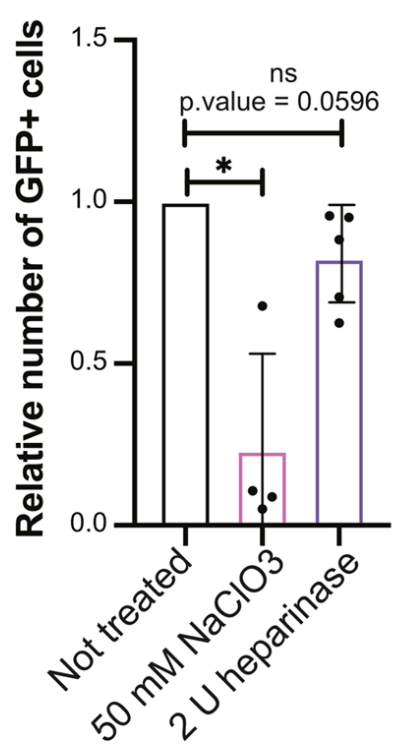

D.

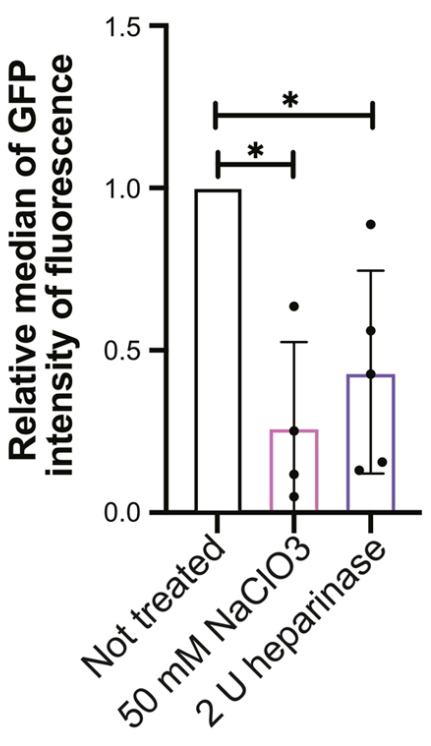

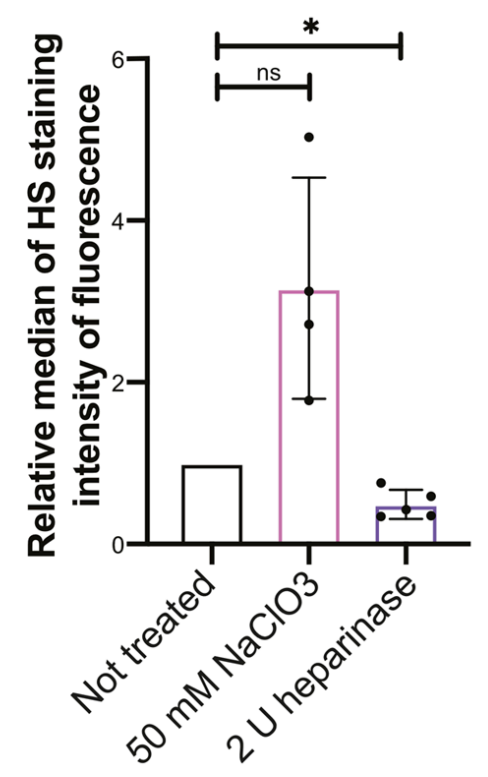

Figure S3 
bioRxiv preprint doi: https://doi.org/10.1101/2020.05.20.105528; this version posted October 14,2020 . The copyright holder for this

preprint (which was not certified by peer review) is the author/funder. All rights reserved. No reuse allowed without permission.

A. B.

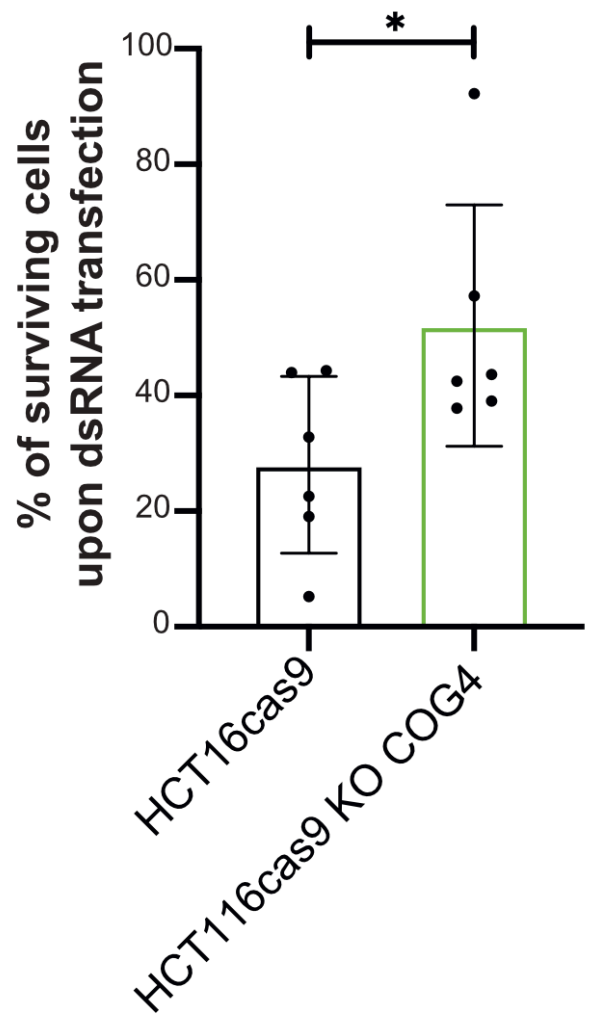

D.
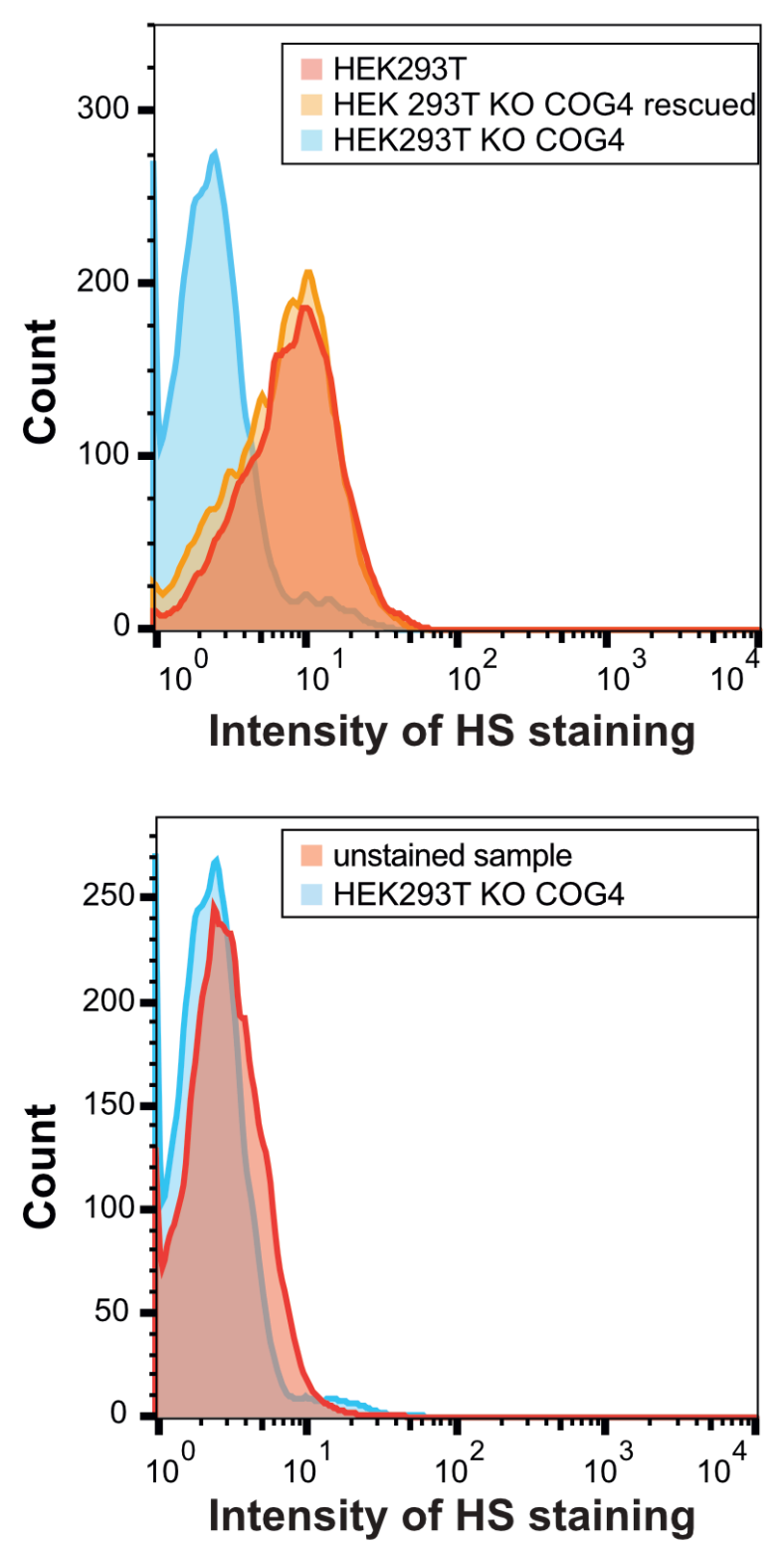

C.
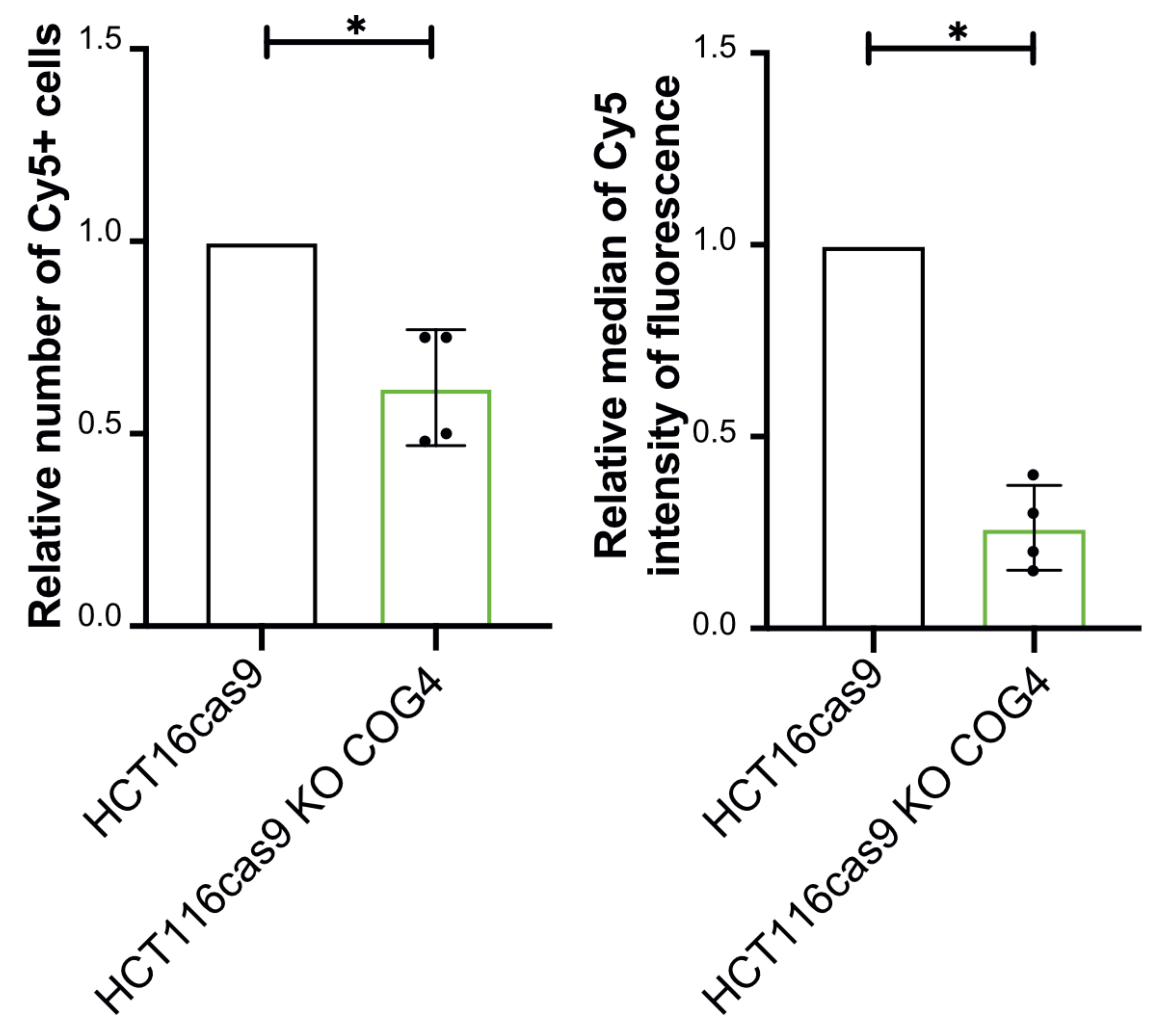

E.

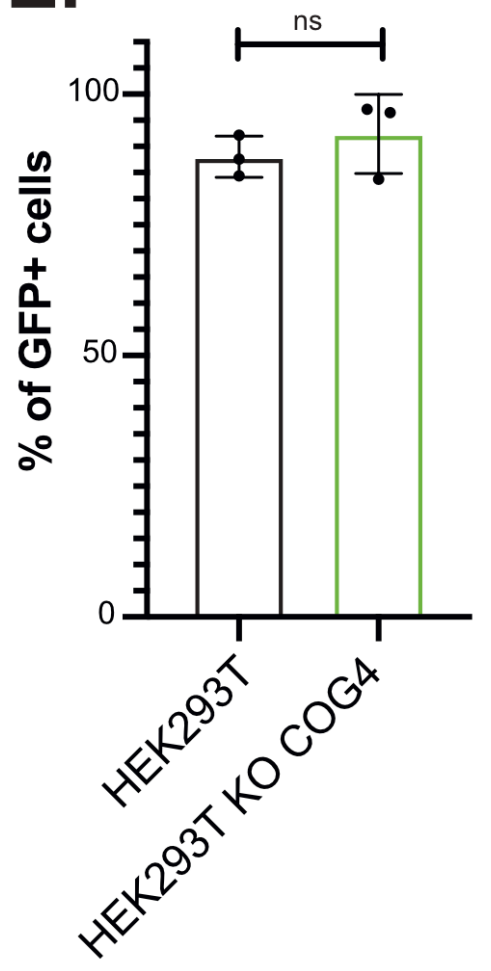

F.

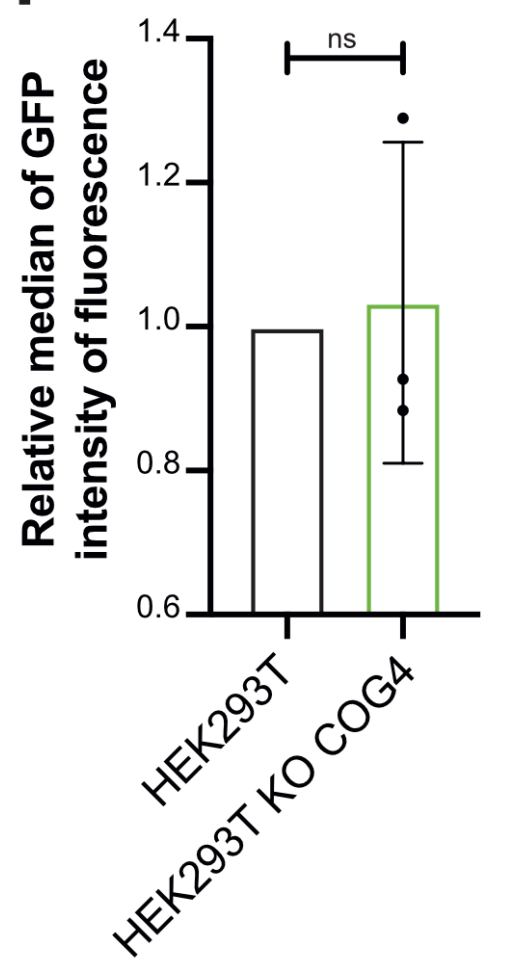


A.

24hpi SINV-GFP
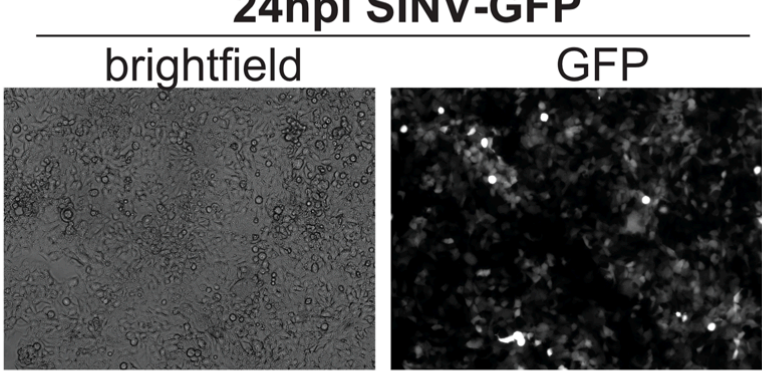

HEK293T KO COG4
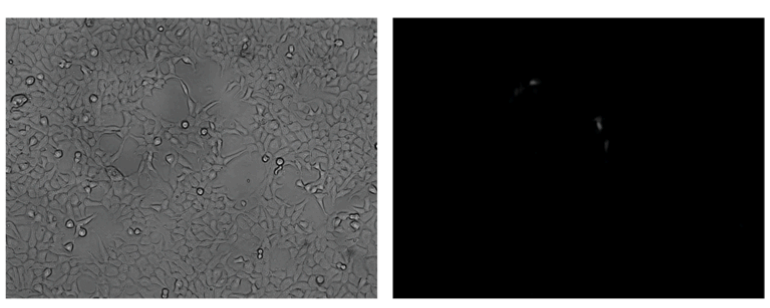

48hpi SINV-GFP
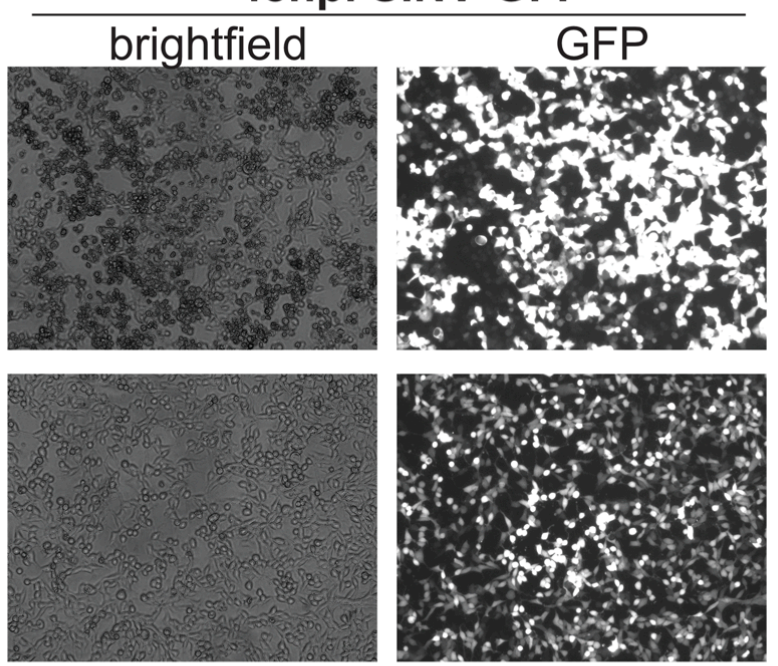

B.
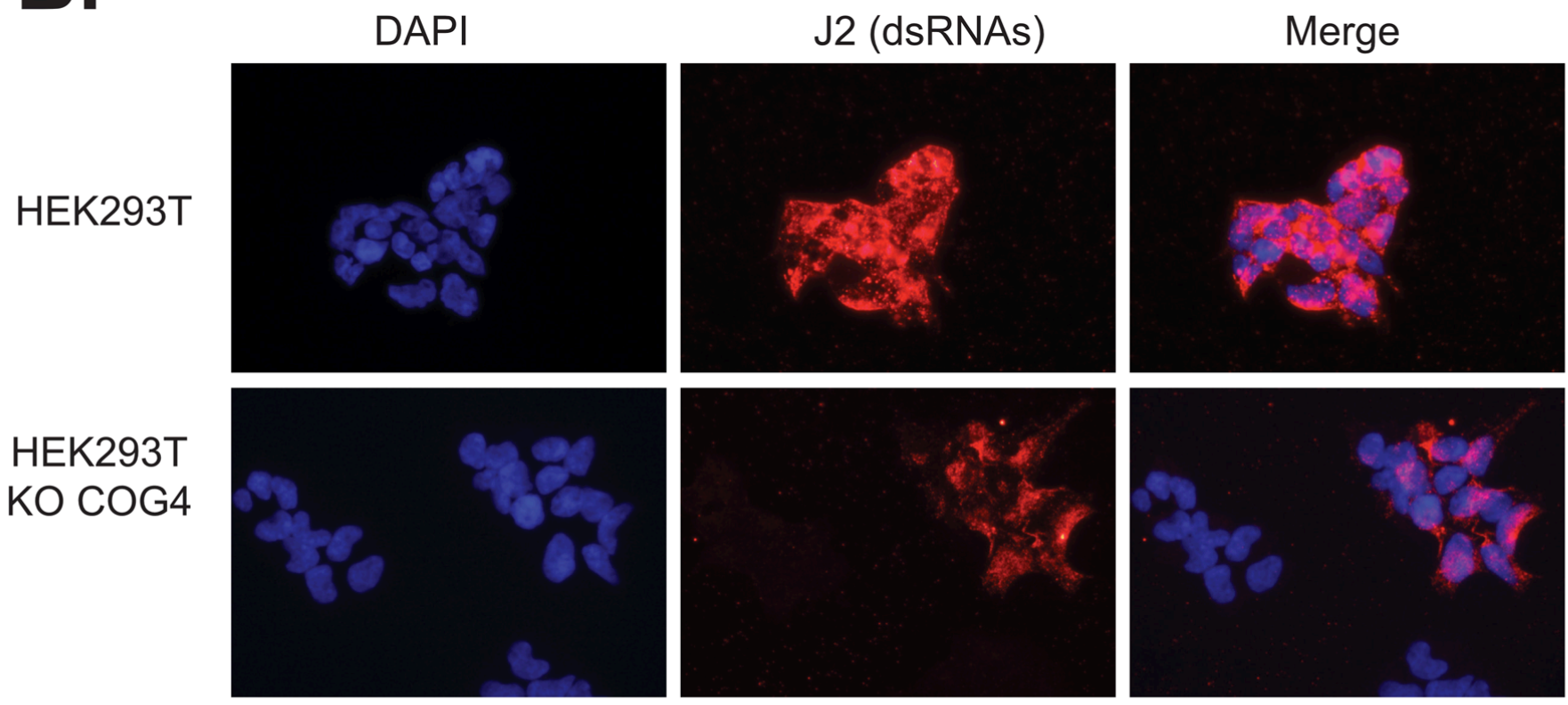

Figure S5 